\title{
Political trust as a cause and consequence of democracy: Longitudinal analysis of European data
}

\author{
Marta Kołczyńska ${ }^{1 *} \&$ Paul-Christian Bürkner ${ }^{2}$ \\ ${ }^{1}$ Institute of Political Studies of the Polish Academy of Sciences \\ ${ }^{2}$ Cluster of Excellence SimTech, University of Stuttgart, Germany \\ * Corresponding author, e-mail: mkolczynska@isppan.waw.pl
}

\begin{abstract}
The causal link between political trust and democratic performance has been assumed rather than established. Building on research on political trust as related to regime legitimacy and on the evaluative nature of political trust, we formulate hypotheses about the effect of political trust on democracy and of democracy on political trust, both with regard to overall levels of trust in societies, as well as trust by education and age groups. We test these hypotheses with cross-lagged models applied to country time series of political trust from 26 European countries between 1991 and 2019, and with two democracy indicators, from the Varieties of Democracy and the Democracy Barometer projects. We find evidence of effects of democracy on trust and vice versa, as well as of differences in the effects of democracy on political trust among different education and age groups. The results are sensitive to the choice of the democracy indicator as well as the lag length, which points to the need of examining different reasonable combinations of indicators and nags in this kind of analysis.
\end{abstract}

\section{Introduction}

The link between political trust and legitimacy, and the fact that any regime needs legitimacy for stability, leads to the expectation that higher political trust contributes to democracies becoming more democratic. At the same time, political trust is often conceptualized as reflecting citizens' assessment of the functioning of state institutions, which would mean that as the country's quality of democracy improves, citizens' political trust should increase. Both statements are widely accepted by sociologists and political scientists, and yet remain largely unverified, as the existing empirical studies on the links between political trust and state performance predominantly rely on cross-national comparisons.

In this paper we ask, after Levi and Stoker (2000, p. 500): Do changes in democratic performance influence citizens' political trust? Does citizens' political trust affect the performance of democracy? Integrating the micro- and macro- perspectives on political trust, we formulate and test hypotheses about the associations between democratic performance and societal levels of political trust. Further, we investigate the consequences of political trust among different societal groups for democracy, and the sensitivity of trust among these groups to changes in democratic governance. Specifically, we build on research that links education to democratic values as well as efficacy and resources, to expect that political trust among people with more education will be more strongly associated with democracy than trust among those with less education. 
Responding to recent concerns with political support among the youth, we analyze changes in democracy as the potential cause of differences in political trust by age groups, and the consequences of age diffences in political trust for democratic governance.

The analysis relies on country time series of political trust estimated with data from 13 international research projects in 26 European countries between 1991 and 2019, combined with country-year level indicators of democratic performance. Recognizing that discrepancies between democracy indicators may affect model results, we use two measures of democracy: from the Varieties of Democracy and the Democracy Barometer projects. We analyze the resulting longitudinal data set with cross-lagged models in a way that takes into account the uncertainty around levels of political trust stemming from the aggregation of survey measurements of population samples. We use lags of varying length to verify the stability of obtained results. The proposed methodological approach sets an example for future rigorous research on the causes and consequences of political attitudes.

We find evidence supporting two out of three hypothesized longitudinal effects of democracy on political trust, with each hypothesis supported by models with one of the democracy indicators but not supported, or supported less strongly, by models with the other indicator. Specifically, our models indicate that improvements in democracy predict increases in overall political trust, and that the probability of a positive effect of democracy on trust is greater among people with more education compared to those with less education. We also find some evidence of effects of overall levels of political trust on democracy, but not of differences in the effect of political trust among different groups on democracy.

The contributions of this research are three-fold. First, our study provides the first rigorous longitudinal analysis of political trust as the cause, and not only as the consequence, of democratic performance. Our finding of weak average effects of democracy on political trust and of trust on democracy, and the variation of these effects across countries, suggest that the close theoretical link between political trust and democracy, supported by numerous cross-national analyses, needs to be rethought. Second, our examination points to differences in the effects of democracy on political trust among different education and age groups. We find that the quality of democracy more strongly predicts political trust among people with more education compared to those with less education. These results provide support for the theoretical understanding of political trust as reflecting the congruence between individual values and values represented by the political system. We also find evidence of weaker effects of democracy on trust among the older adults compared to the youth - a finding that warrnats further investigation. Third, we propose a methodological approach that addresses challenges faced by researchers interested in longitudinal analyses of mass public opinion. Our measure of political trust is aggregated from different surveys that have not a priori been designed with comparability in mind. We take the uncertainty around the estimate of average political trust explicitly into account in models, which is particularly important if the uncertainty is relatively high compared to the variable's variability. Recognizing the potential sensitivity of results to the choice of the democracy indicator and lag length, we use two democracy indexes created by two different research groups, and model a range of reasonable lags of between one and five years. We also leverage the ability of Bayesian methods to quantify uncertainty in a way that provides a more holistic picture of the studied associations.

\section{Political trust and democracy}

Legitimacy refers to "the capacity of a political system to engender and maintain the belief that existing political institutions are the most appropriate and proper ones for the society" (Lipset, 1983, 64). Understood 
this way, legitimacy presupposes citizens' political support, which is sometimes considered an aspect of legitimacy (Dalton, 2004; Tyler and Jackson, 2013), its consequence (Thomassen and van Ham, 2017), or cause (Hough et al., 2010). All these approaches conceptualize political legitimacy as intimately linked to political support, which includes trust in state institutions, a middle-range indicator corresponding to support for the regime (Easton, 1965, 1975) or to support for regime institutions (Norris, 1999, 10).

Defining trust as a "rational or affective belief in the benevolent motivation and performance capacity of another party" (Norris, 2011, 19) draws attention to the evaluation of motivation and performance as sources of trust. Correspondingly, most empirical studies linking political trust and the quality of democracy treat democracy as the cause and trust as the outcome. For example, a recent longitudinal study found that changes in the quality of government lead to higher trust in parliament, political parties, and government (Martini and Quaranta, 2020).

Political trust is also expected to influence political systems, hence the concern with trusts' alleged decline: "If trust matters, then it should also be apparent at the system level in the patterns of governance and government" (Dalton, 2004, 162). This influence is hypothesized to operate via multiple mechanisms, such as compliance with the law, including tax compliance, and political participation, especially electoral turnout (Dalton, 2004; Lussier, 2016). Indeed, research has shown that high political trust is associated with higher compliance with civic duty and government regulation (Letki, 2007; Tyler, 1990), which most recently manifested during the COVID-19 pandemic (Ezeibe et al., 2020; Devine et al., 2020).

The political culture literature considers political participation as crucial to democracy, and trust as requisite for political participation, as purposeful actors need to believe in the responsiveness of the state and in the possibility of political success of their actions (Almond and Verba, 1963). Empirical studies show that, in European democracies, people with higher levels of political trust are more likely to engage in both institutionalized and non-institutionalized political participation (Schnaudt, 2019). Beyond these behavioral consequences, political support is also theorized to have affective and cognitive effects that are conducive to the strengthening of democracy and its institutions (Dalton, 2004, 157-187). As citizens become disappointed with the provision of public services, they may be more inclined to switch over to private solutions, thus increasing the alienation and weakening their connection to the state.

The question whether political trust translates into better democratic performance, and consequences of political trust more generally, remain understudied (van der Meer, 2017). ${ }^{1}$ Our study fills in this gap by testing whether increases in societal levels of political trust predict increases in democracy (Hypothesis 1), as well as whether the opopsite is true as well, i.e. whether improvements in democratic quality predict increases in political trust (Hypothesis 2).

\subsection{Education}

Associating country-level outcomes, such as democratic performance, with mean levels of attitudes in the society as a whole is based on the implicit but strong assumption that individuals within a society are

\footnotetext{
${ }^{1}$ The only study, to the best of our knowledge, that examines political trust as a potential cause of democratic performance analyzes longitudinal associations between different political values and attitudes and democracy, finding that "institutional confidence negatively predicts future democracy" (Ruck et al., 2020, 266). However, the results of this study are difficult to interpret due to the authors' methodological choices. Based on the assumption that "cultural values are formed during the first few decades of life" (Ruck et al., 2020, 265), the authors use data from the World Values Survey and European Values Study collected between 1990 and 2015, and assign levels of values such as openness and attitudes such as political trust based on respondents' cohorts of birth, resulting in a longitudinal dataset starting in 1900. This decision is questionable, given that political trust is known to be volatile and to react strongly to contemporary events.
} 
interchangeable with regard to their influence on political performance - a contradiction to much of social science theory. In the next sections we consider whether the distribution of political support across social groups - in this case defined on the basis of education and age - can be informative in explaining the links between political trust and democracy.

Education has long been recognized as a powerful predictor of civic engagement (Putnam, 2000). Education is associated with more liberal values and democratic orientations (Bobo and Licari, 1989; Hyman and Wright, 1979; McClosky and Zaller, 1984), political competence (Milligan et al., 2004), as well as with an with aversion to radical right-wing parties (Cornelis and Van Hiel, 2015; Lubbers et al., 2002) and populist parties (van Kessel et al., 2020). Further, cross-national comparisons show that individuals with more education tend to be more democratically oriented regardless of the democraticness of their country of residence (Chong and Gradstein, 2015).

The relationship between education and political trust is more complex. Cross-country comparisons have found that this relationship depends on the country's level of democracy and corruption: In countries with better quality of democracy and less corruption, trust is positively related to education, but in non-democratic countries and those that struggle with widespread corruption, the relationship between education and political trust in negative (Hakhverdian and Mayne, 2012; Kołczyńska, 2020). Hakhverdian and Mayne (2012) and Mayne and Hakhverdian (2017) explain these regularities by pointing to the accuracy-inducing and norminducing roles of education, which make individuals with more education have acquired norms of democratic governance as well as the capacity to assess whether they are met to a greater extent than those with less education.

If the same mechanism operates in the longitudinal perspective, it could be expected that as countries become more democratic, the education gap in political trust would become larger. On the other hand, democratic backsliding would reduce the "trust bonus" among more educated groups compared to the less educated. The only study that purports to answer this question directly is, to the best of our knowledge, the analysis by Martini and Quaranta (2020), who used Eurobarometer data from 1995-2017 to explore the effects of economic performance, quality of governance, and income inequality on the education gap in political trust. They found between-country, but not within-country, effects of governance on the education gap in political support.

So far we have considered political trust as reflecting the interaction between individual education and the country's democracy. It is also possible that political trust has a different effect on democracy depending on who expresses it. Specifically, the effect on democracy of political trust among individuals with more education may be different from the effect of trust among people with less education. More educated people are more politically competent (Milligan et al., 2004), more likely to participate in civic and political life, including membership in voluntary associations (Putnam, 2000) and political parties (Norris, 2002), electoral and non-electoral political participation (Hooghe and Marien, 2013; Smets and van Ham, 2013; Dalton et al., 2010; Aars and Strømsnes, 2007), as well as more likely to report crimes to the police (Botero et al., 2012). With the exception of some forms of protest participation (cf. Hooghe and Marien, 2013), these behaviors are also more likely among individuals with higher political trust. There are reasons to believe that political actions by educated citizens are more effective, owing to the resources and networks of which more educated people tend to have more than the less educated. Higher political trust thus results in higher rates of political engagement and civic participation of individuals with democratic orientations who are better equipped to achieve their goals.

Based on the above, we formulate two additional hypotheses. First, we expect that increases in the quality of 
democracy more strongly predict increases in political trust among people with more education than among those with less education (Hypothesis 3). Second, we expect that political trust among people with more education more strongly predicts increases in democratic quality than political trust among people with less education (Hypothesis 4).

\section{$2.2 \quad$ Age}

The role of age or - more specifically - of the youth became subject to heated debates following Foa and Mounk's $(2016 ; 2017)$ papers on the alleged decline of democratic support among the young in established democracies. Numerous, predominantly critical, responses found little evidence for the alarmist tone (i.a., Alexander and Welzel, 2017; Voeten, 2017; Zilinsky, 2019; Wuttke et al., 2020), but the broader discussion warrants the question about the relative importance of political values and attitudes among the youth from the point of view of democratic governance.

Young people engage less in conventional political participation compared to older adults. According to data from the European Social Survey between 2002 and 2019 (European Social Survey, 2020), people aged 18-30 are less likely than other age groups to work for political parties, action groups, or other organizations, to contact politicians, and to exhibit interest in political issues. The largest participation gap, however, pertains to voting in elections, where voters aged below 30 consistently declare the lowest participation rates.

Whether the low turnout among the youth represents a life-cycle effect (e.g., Wolfinger and Rosenstone, 1980; Smets, 2016; Quintelier, 2007), a habit-formation effect (Plutzer, 2002), or a generation effect (Blais et al., 2004; Wass, 2007), the fact remains that young people are less likely to vote. If legislators use turnout as a signal of public scrutiny and react to higher turnout with greater policy responsiveness, as Martin and Claibourn (2013) argue, then low turnout among the younger cohorts would translate to less responsiveness towards the interests of the youth. Young people also tend to be underrepresented in legislatures, as indicated by the Youth Representation Index, which compares the proportions of members of parliaments aged 18-35 and 18-40 to the respective shares of these age groups in the general populations (Sundström and Stockemer, 2020). On the other hand, the young are more likely than older people to engage in protest activities, such as demonstrations or signing petitions (Quintelier, 2007), which have largely become part of the normal repertoire of politics in democratic countries (Meyer and Tarrow, 1998; Newton and Montero, 2007).

Overall, the young seem to be the group with relatively low political power, in terms of participation in most forms of political life, parliamentary representation, as well as in terms of resources which can be used to exert political influence. Thus, from the point of view of political influence, young people, and the political attitudes they hold, are expected to have less influence on the democratic governance than older age groups ${ }^{2}$.

Turning to age gaps in the effects of democracy on political trust, theory points to possible differences in the expectations young people have of the state and politics. Franklin and Riera (2016) argue that younger generations of Europeans expect dynamic (responsive) representation, where governments respond to public demands and are accountable throughout the electoral cycle, rather than being satisfied with descriptive representation rooted in cleavage politics. Using data from the Democracy rotating module from the European Social Survey Round 6, they show that younger people tend to more often prefer the idea of "mandate

\footnotetext{
${ }^{2}$ The only study that examines the consequences of the age gap in political trust for democratic quality that we are aware of by Kwak et al. (2020) - expects and finds a positive effect of the age gap in political trust, defined as the ratio of political trust among the youth divided by trust among older respondents, on future levels of democracy, but with a different set of countries, few measurements per country over a short period of time, and with methodological decisions regarding especially constructing a comparable measure of political trust differences between age groups that make their results uninformative for our purposes.
} 
representation", where governments are expected to adapt their policies to public opinion, over "trustee representation", which involves sticking to the government's platform regardless of what the public thinks. Thus, political trust among young people may be more sensitive, especially to whether they feel represented or not. The difference in expectations between young and older adults may also stem from differences in values, as younger people are known to be more liberal, open, and focus on self-expression (Norris and Inglehart, 2019).

Based on these considerations, we expect that political trust among the young will have a weaker effect on democratic quality than political trust among the older cohorts (Hypothesis 5). We also expect changes in the quality of democracy to more strongly predict political trust among the young than among older adults (Hypothesis 6).

\section{Analytic strategy}

The analytic strategy we propose includes several components. First, we use of model-based estimates of political trust levels as well as the uncertainty around them, reflecting the nature of these estimates as derived from survey samples rather than quantities observed without error. Second, we estimate cross-lagged models, which enable us to explore the associations between political trust and democracy in both directions. Third, we use different lag lengths to gain more insight into the nature of the studied relationships. Fourth, the use of indicators of democracy from two different sources enables us to verify the whether our results are driven by the choice of a particular democracy index. We elaborate on these components in the remainder of this section.

\subsection{Data}

\subsubsection{Political trust}

To measure country-year levels of political trust in Europe between 1991 and 2019, both overall, and by education and age groups, we use poststratified estimates created by jointly analyzing data from 13 crossnational survey projects with hierarchical Item Response Theory models. These models were applied to survey variables referring to trust in national parliaments, political parties, and justice systems as indicators of political trust (see Kolczynska et al., 2020, for more details about the data and models, and the Online Supplement for the list of source data sets). We use estimates of levels of political trust overall, as well as by education and age. Education is coded in three categories: below completed secondary education, secondary education and post-secondary non-tertiary education, and tertiary education or above. We coded age in three categories: 20-34, 35-54, and 55-74. Estimates for education groups were poststratified by sex and age, while estimates by age groups were poststratified by sex and education.

\subsubsection{Democracy}

Longitudinal research with democracy indicators poses certain challenges. First, there are many approaches to conceptualizing, operationalizing, and measuring democracy, resulting in a choice of datasets and indicators produced by different research projects and organizations. While across countries these different democracy indicators are relatively consistent, country trajectories are characterized by considerable discrepancies, as 
Kołczyńska and Bürkner (2020) point out. We use democracy indicators from two datasets created by well respected research groups: the Varieties of Democracy project (Coppedge et al., 2020) and the Democracy Barometer project (Engler et al., 2020), to avoid the risk of results being driven by the choice of a particular index.

Second, some democracy indices - for example those published by the Varieties of Democracy project are model-based and provide uncertainty estimates, which should be taken into account in analyses. In many cases the uncertainty associated with these democracy indices is very high compared to the changes in the estimates over time. For example, as shown in Figure 1, which presents all the variables used in the analysis standardized to have a mean on 0 and unit standard deviation, changes in the level of democracy as measured by V-Dem's Liberal Democracy Index in many European countries have been smaller than the uncertainty estimates representing two standard deviations of respective posterior distributions (cf. Coppedge et al., 2020, p. 30). V-Dem's practice of quantifying the uncertainty of their democracy scores is no doubt commendable. However, such high uncertainty and small changes make it virtually impossible to model the data longitudinally. We decided to use democracy scores without the accompanying uncertainty, which is the standard practice in the scholarly literature on the topic anyway. We note that this decision likely affects the magnitude and significance level of the observed effects, but not their direction.

The V-Dem Liberal Democracy Index captures the respect for freedoms and liberties as well as controls placed on the government, in addition to meeting requirements of electoral democracy, i.e. free and fair elections (cf. Coppedge et al., 2020, p. 42-43). The index is based on expert responses to a standardized questionnaire, which are aggregated with Bayesian factor analysis into sub-indicators and then combined into target indicators.

The concept of democracy assumed by the Democracy Barometer is broader, and the index was explicitly designed to "measure the subtle differences in the quality of established democracies" (Engler et al., 2020, p. 6). Democracy Barometer uses data from various sources, including aggregated cross-national surveys, dataset created by researchers, as well as by institutions and organizations, such as the World Economic Forum, Fraser Institute, statistical offices, among others. In addition to individual liberties, rule of law, freedom of expression, mutual constraints of constitutional powers, which are part of the V-Dem Liberal Democracy Index, the Democracy Barometer index also includes measures of government capability, transparency, and political participation.

The dimensions of the Democracy Barometer index are not straightforward to map onto the concepts of the V-Dem Liberal Democracy index. To make the two indexes more comparable, from the Democracy Barometer data we selected the Individual Liberties, Rule of Law, and the Public Sphere components from the Freedom principle, and the Mutual Constraints component from the Control principle, and combined them following the recommended aggregation rules (Engler et al., 2020, p. 8-9) ${ }^{3}$.

\footnotetext{
${ }^{3}$ Among the source data, the Democracy Barometer index includes measures of confidence in the justice system and in the police from some of the same cross-national surveys from which we derived the political trust measures. We excluded these components from the aggregation procedure.
} 


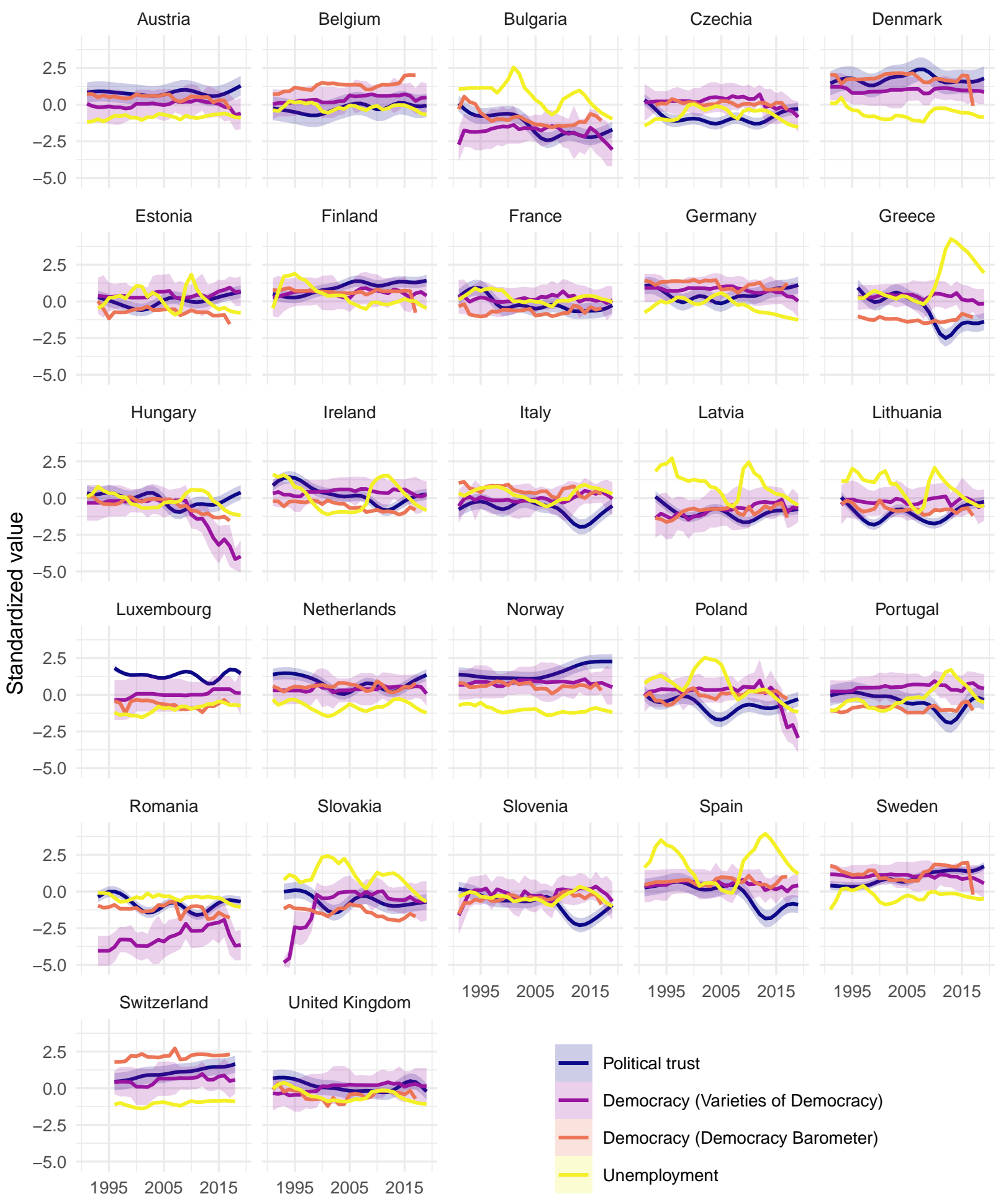

Figure 1: Trends in political trust, democracy according to the Varieties of Democracy and the Democracy Barometer indicators, and unemployment. All variables have been standardized with the sample of country-years. Intervals where available - indicate +/- two standard deviations of posterior distributions. 


\subsubsection{Economic performance}

We use the unemployment rate, provided by the Eurostat (Eurostat, 2020), as a measure of the economic situation, since political trust is known to be associated with macro-economic conditions (van Erkel and van der Meer, 2016; Martini and Quaranta, 2020; Obydenkova and Arpino, 2018). Economic conditions constitute a signal of the state's capacity of securing a favorable economic environment for the society in line with the widespread public belief that it is the government's responsibility to deliver high levels of economic performance (Clarke et al., 1993). The number of countries in our analysis restricts the number of predictors we can include, and we decided that unemployment best captures the direct effects of economic performance on people's lives, operating on two levels. High unemployment increases labor market insecurity for all employees, which has a negative effect on political trust (Wroe, 2014). High unemployment also has direct negative consequences for the most affected individuals who lose or are unable to secure good jobs, which reduces life satisfaction and self-esteem, and is associated with negative perceptions of the political system blamed for the individual's misfortunes (Bauer, 2018). Figure 1 presents the trends in unemployment, political trust, and the democracy indicators.

\subsection{Models}

The literature provides little guidance as to the expected lag between the hypothesized cause and effect in analyses of political attitudes and democracy. If the mechanism whereby political trust affects democratic performance operates through elections, then a lag of four-five years, corresponding to the length of the electoral cycle, would be appropriate. It is not likely that the association only appears for one particular length of the lag, so testing different lags would reveal whether associations are consistent or whether one particular lag length stands out as a possible data artifact. Practical considerations are not irrelevant either. The longer the lag, the shorter the time series available for modeling. Since political trust levels for most of the countries in our dataset start in 1990 and end in 2019, having lags longer than five years would substantially reduce our dataset. Thus, we decide to use lag lengths of between one and five years.

To analyze the relation of trust and democracy, while accounting for variation across countries and time, as well as for economic influences we applied Bayesian cross-lagged multilevel models (Schuurman et al., 2016; Gelman et al., 2013). For each individual model, the dependent variables are (1) trust in political institutions and (2) measures of democracy we denote the vector of dependent variables of country $j$ at year $t$ as $\left(y_{j t 1}, y_{j t 2}\right)$, where $y_{j t 1}$ is the trust in political institutions in country $j$ and time $t, y_{j t 2}$ is the corresponding democracy score. For easier interpretation and comparison, both dependent variables are standardized on the overall mean and standard deviation across countries and time. The dependent variables are assumed to be multivariate normally distributed with mean vector $\left(\mu_{j t 1}, \mu_{j t 2}\right)$ and residual covariance matrix $\Sigma$ :

$$
\left(y_{j t 1}, y_{j t 2}\right) \sim \operatorname{normal}\left(\left(\mu_{j t 1}, \mu_{j t 2}\right), \Sigma\right)
$$

The individual elements of the mean vector $\mu_{j t k}(k=1,2)$ are then predicted by a cross-lagged model as follows:

$$
\mu_{j t k}=\beta_{j k 0}+\sum_{l=1}^{L} \beta_{j k l} x_{j t l}+\sum_{m=1}^{2} \gamma_{j k m} y_{j(t-\tau) m},
$$

where $\beta_{j k 0}$ denotes the intercept, $\beta_{j k l}$ denote the slopes of cross-sectional control variables $x_{j t l}, \gamma_{j k m}$ denote the slopes (cross-lagged coefficients) of dependent variable $m$ on dependent variable $k$, and $\tau$ indicate the length of the lag (e.g., $\tau=1$ for a cross-lagged model based on the directly preceding year). In our main 
models, the only included cross-sectional control variable was the unemployment rate as a measure of the state of the economy. To account for the dependency between countries and allow the model to share information across countries, we assume a multilevel model over the regression coefficients $\left(\beta_{j k 0}, \ldots, \beta_{j k L}, \gamma_{j k 1}, \gamma_{j k 2}\right)$ as

$$
\left(\beta_{j k 0}, \ldots, \beta_{j k L}, \gamma_{j k 1}, \gamma_{j k 2}\right) \sim \operatorname{normal}\left(\left(\beta_{k 0}, \ldots, \beta_{k L}, \gamma_{k 1}, \gamma_{k 2}\right), \Lambda_{k}\right)
$$

where $\left(\beta_{k 0}, \ldots, \beta_{k L}, \gamma_{k 1}, \gamma_{k 2}\right)$ are the average coefficients across countries and $\Lambda_{k}$ is the multilevel covariance matrix of dependent variable $k$. For ease of interpretation, the covariance matrices $\Sigma$ and $\Lambda_{k}$ are each parameterized in terms of a vector of standard deviations and a correlation matrix (Bürkner, 2017).

In our models, measures of democracy were treated as directly observed without error. In contrast, for the trust variable (which we assume to have index 1 without loss of generality), we employed an additional error-in-variable approach (Reilly and Patino-Lea, 1981). That is, we treat $y_{j t 1}$ as a latent variable related to the data as

$$
\tilde{y}_{j t 1} \sim \operatorname{normal}\left(y_{j t 1}, s_{j t 1}\right),
$$

where $\tilde{y}_{j t 1}$ is the mean trust value and $s_{j t 1}$ is the standard deviation of trust for country $j$ at time $t$ both obtained from the trust prediction model of Kolczynska et al. (2020).

In a second analysis step, we studied the relevance of trust variations across age and education categories. For this purpose, we included additional coefficients to the linear model (2) for both the main effects of age or education, as well as their interactions ${ }^{4}$ with the cross-lagged trust variables $y_{j(t-\tau) 1}$. These coefficients were also assumed to vary over countries and hence added to multilevel model (3). To keep the model complexity manageable, only one of the two demographic variables were included in the model at a time. Since the democratic measures considered in this study do not vary across age or education for obvious reasons, the latter variables were not used to predict democratic measures in our models.

Priors for all (hyper-)parameters were chosen as weakly-informative, thus having only minimal influence on the obtained inference while ensuring sufficient sampling efficiency (Gelman et al., 2008). Models were estimated and post-processed using the probabilistic programming language Stan (Carpenter et al., 2017) and the R package brms (Bürkner, 2017) which provides a high-level interface to Stan. Inference on central model parameters is reported in terms of posterior means (point estimate; denoted as $\beta$ ), quantile-based $95 \%$ posterior uncertainty intervals (i.e., credible intervals; CIs), and posterior probabilities that the effects are positive (Gelman et al., 2013). By interpreting posterior probabilities as a continuous measure of evidence in favor of (or against) the expected effects, we deliberately avoid binary decision making enforced by the classical approach of 'statistical significance'.

The models proved to be a challenge to estimate. Initially our analysis included data from all 27 countries for which we have political trust estimates, and are presented in Figure 1. Because of severe model convergence problems caused by the data from Poland, we decided to exclude this country from the main analysis, and in the next sections we present results for models estimated with data from the 26 remaining countries. Equivalent models including Poland are included in the Online Supplementary Materials. Even after excluding Poland, the models had difficulties estimating a handful of varying coefficients, but we believe that this did not affect the overall coefficients that are of interest to our analysis. We provide more information on the non-converging parameters in the Supplement.

\footnotetext{
${ }^{4}$ Some researchers may prefer using difference scores instead of interaction effects. However, difference scores are essentially just a special case of interaction effects induced by restrictive assumptions that are usually not met in practice (e.g., Edwards, 1994).
} 
Given the large number of models for different lag lengths and democracy indicators, in the next sections we only discuss the coefficients of interest, while the full model outputs are available in the Online Supplement. In the description of results, we use the term "effect" to refer to the estimated cross-lagged coefficients, being aware of the limitations of statistical models in testing causal claims.

\section{Results}

\subsection{Overall levels of political trust and democracy}

\subsubsection{Effects of trust on democracy}

The first part of the analysis focuses on the bi-directional lagged effects between democracy and overall political trust. Figure 2 presents coefficients corresponding to the average lagged effects of political trust on democracy, and of democracy on political trust, for the two measures of democracy, from the V-Dem and DB projects, and for lags of between one and five years.

The two top graphs in Figure 2 show coefficients and corresponding 95\% uncertainty intervals of the average effect of political trust on democracy across all countries, using the V-Dem democracy indicator (left) and the Democracy Barometer index (right). In models using the V-Dem indicator for the one-year lag, the coefficient for the effect of trust on democracy equals $\beta=0.04,95 \%$-CI $=[0.00,0.08]$, and becomes even weaker and associated with substantially more uncertainty for longer lags. The probability of the effect being greater than 0 equals 0.98 for the one-year lag, drops to 0.69 for the two-year lag, and below that for longer lags (see the $V$-Dem column in the left part of Table 1). When using the DB index, the coefficients are also positive, and posterior probabilities of the effect being positive equal between 0.86 for the three-year lag and 0.94 for the five-year lag (as shown in the $D B$ column in the left part of Table 1).

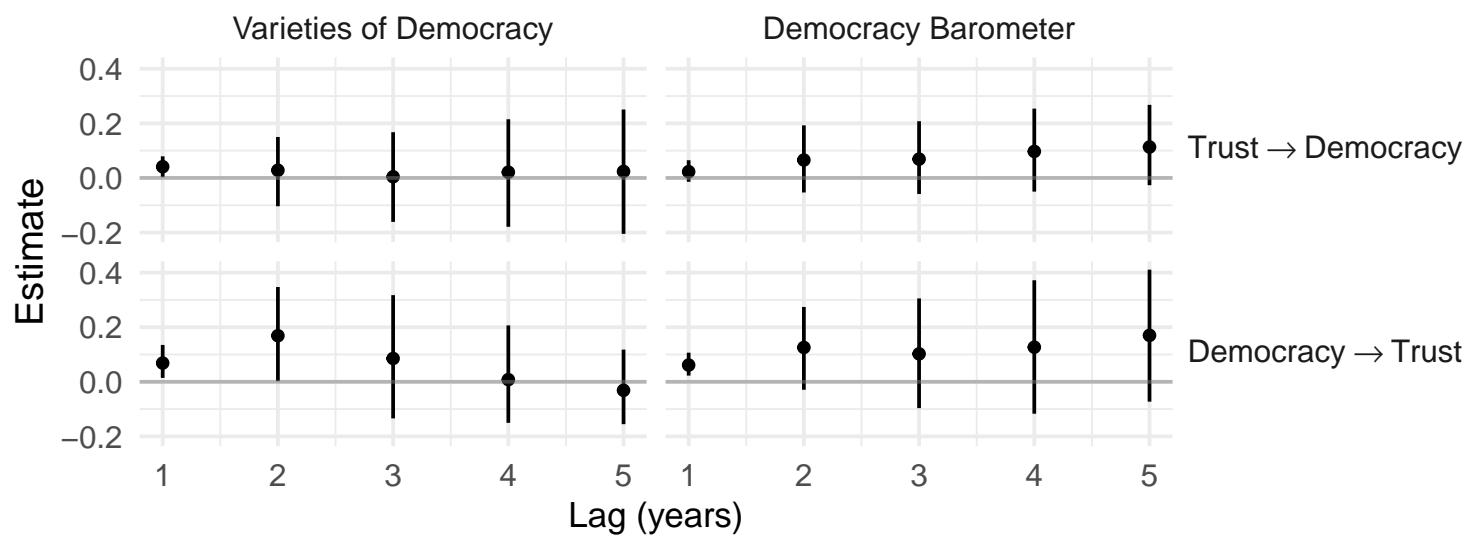

Figure 2: Effect estimates of democracy on political trust and vice versa from models with the Varieties of Democracy and Democracy Barometer indicators for different lag lengths. Points indicate posterior means and error bars indicate $95 \%$ credible intervals.

When comparing by-country effects presented in Figures 5 and 6 , the only country in which trust has a clearly positive effect on democracy measured by both indicators is Hungary. There the effect results from the declines in political trust during much of the 2000s followed by a substantial deterioration in democracy, 
Table 1: Posterior probabilities of the effects being positive.

\begin{tabular}{lccccc}
\hline & \multicolumn{2}{c}{ Trust $\rightarrow$ Democracy } & & \multicolumn{2}{c}{ Democracy $\rightarrow$ Trust } \\
\cline { 2 - 3 } \cline { 5 - 6 } Lag & V-Dem & DB & & V-Dem & DB \\
\hline 1 & 0.98 & 0.88 & & 0.99 & $>0.99$ \\
2 & 0.69 & 0.87 & & 0.98 & 0.95 \\
3 & 0.52 & 0.86 & & 0.78 & 0.85 \\
4 & 0.59 & 0.90 & & 0.50 & 0.85 \\
5 & 0.58 & 0.94 & & 0.29 & 0.92 \\
\hline
\end{tabular}

Note: Results are based on the same models as shown in Figure 2.

as shown in Figure 1. Since then, trust has rebound and indeed currently nears its maximum levels, but democracy continued to fall. Although many other European countries have seen similarly strong declines in political trust during the studied period, in none of them were these declines followed by strong drops in democratic quality. If declines in political trust create favorable conditions for illiberal or populist parties to gain support, whether these parties take over power and successfully implement their reforms depends on other factors not accounted for in the analysis (cf. Weyland, 2020).

\subsubsection{Effects of democracy on trust}

The estimated effect of democracy on trust is presented at the bottom of Figure 2. For one-year lags the effect is small (for V-Dem $\beta=0.07, \mathrm{CI}=[0.01,0.14]$, and for $\mathrm{DB} \beta=0.06, \mathrm{CI}=[0.02,0.11]$ ) but in both cases the probabilities of positive effects exceed 0.99 (right side of 1). For longer lags, coefficients in models with the DB indicator stay roughly the same with increasing uncertainty, and probabilities of the effect being positive range between 0.85 and 0.95 . In models using the V-Dem index, the coefficient increases for the two-year lag, with a 0.98 probability of the effect being positive, and declines substantially for longer lags. Figures 5 and 6 again point to large variation in by-country effects.

These results provide some support for the hypothesized bi-directional lagged effects between democracy and political trust, based on models using the DB indicator, according to which the probabilities of positive effects in both directions exceed 0.85 for all lag lengths. For the effect of trust on democracy, the probability of a positive effect is the highest for the longest lag of five years, while for the effect of democracy on trust the highest probability of a positive effect is for the shortest one-year lag. In models that use the V-Dem indicator of democracy, the probabilities of positive effects in both directions are the strongest for one-year lags, and fade for longer lags. It is worth noting that the interpretation of the effect of trust on democracy in models with the DB indicator would be different if the uncertainty in the estimates of trust levels was ignored. These latter models, presented in the Online Supplementary Materials, indicate essentially no effect of trust on democracy in models with the DB index of democracy.

\subsection{Political trust by education level}

\subsubsection{Effects of trust on democracy}

We now turn to differences in the bi-directional effects of trust and democracy by education level, presented in Figure 3 based on models with the V-Dem democracy index (left) and from models using the DB index 
(right). Plots in the upper part represent the interaction effects of trust among people with secondary and tertiary education, respectively, compared to those with primary education, on democracy. In models with the V-Dem indicator, for both levels of education, the coefficients are very small and uncertainties comparably large, which means that there is little difference in the effect of trust among education groups on democracy. Correspondingly, posterior probabilities of the difference in the effects of trust on democracy by education being positive, presented in Table 2 (columns Sec.-Prim. and Tert.-Prim. in the left hand side of the upper panel), are quite close to 0.5 .

Models with the DB indicator indicate a weak interaction between both higher levels of education and the effect of trust on democracy, but in the opposite direction that the theory would predict. According to these models, the posterior probability of the effect of trust among people with tertiary education on democracy being greater than the effect of trust among people with primary education on democracy ranges between 0.83 and 0.92 depending on the lag (column Tert.-Prim. on the right side of the upper panel of Table 2). By-country slopes, in Appendix 2, also show that in virtually all countries the interaction effect is negative, even if very small.
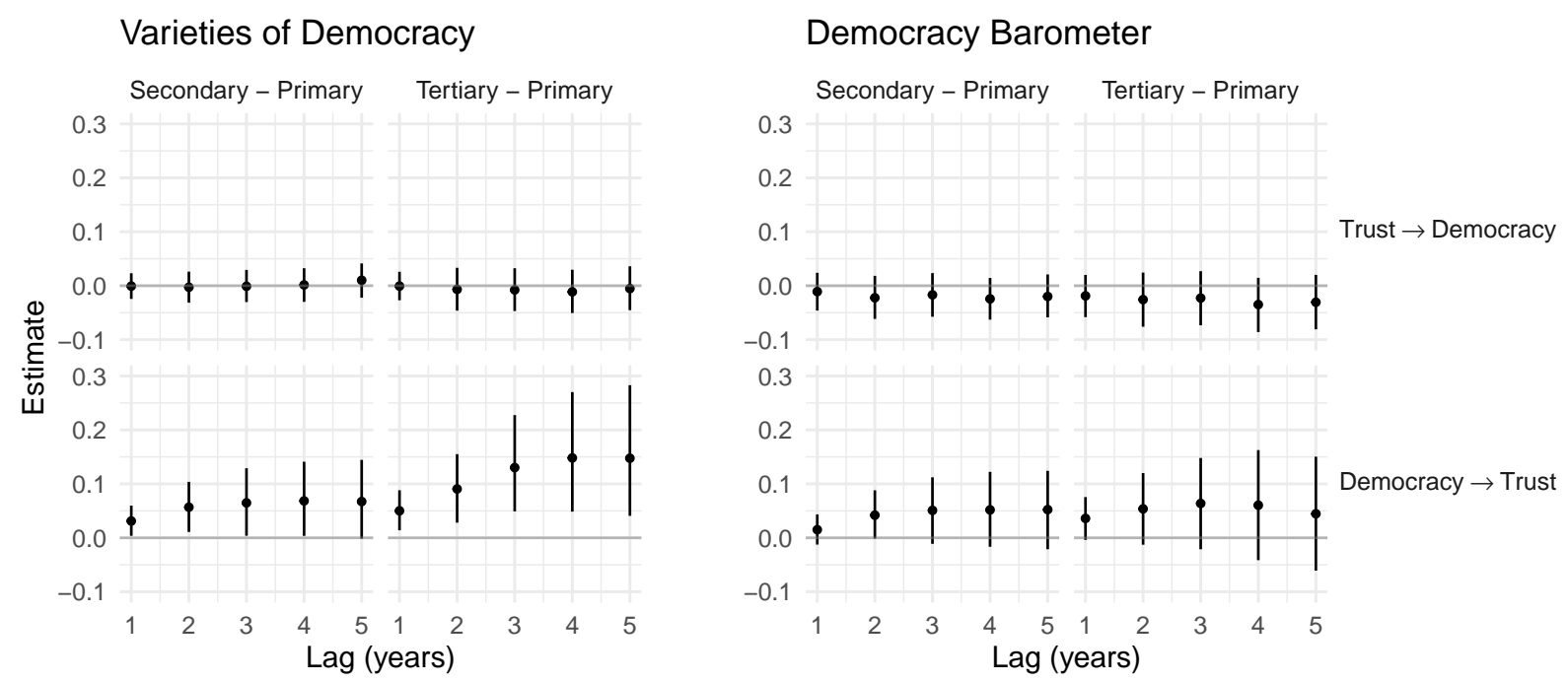

Figure 3: Interaction effect estimates of democracy on political trust and vice versa, for secondary and tertiary education with primary education as the reference category, for different lag lengths. Models use the Varieties of Democracy and Democracy Barometer indicators. Points indicate posterior means and error bars indicate $95 \%$ credible intervals.

\subsubsection{Effects of democracy on trust}

The bottom part of Figure 3 presents the effects of democracy on political trust in interaction with education. Results are shown for the differences between secondary and tertiary education, respectively, with primary education as the reference category. Here the effects are clearer, with interaction coefficients being positive for all combinations of democracy indicators and lags. In models using the V-Dem democracy index, the interaction coefficient for secondary education (vs. primary education) for the one-year lag equals $\beta=0.03$, $\mathrm{CI}=[0.00,0.06]$, and $\beta=0.07, \mathrm{CI}=[-0.00,0.14]$, for the five-year lag. For tertiary education, the interaction coefficient equals $\beta=0.05, \mathrm{CI}=[0.01,0.09]$, for the one-year lag and $\beta=0.15, \mathrm{CI}=[0.04,0.28]$, for the five-year lag. When using the DB index, the corresponding interaction coefficients are smaller, ranging from 
Table 2: Posterior probabilities of the effects being positive, by education level.

\begin{tabular}{|c|c|c|c|c|c|c|c|c|c|c|}
\hline \multirow[b]{2}{*}{ Lag } & \multicolumn{5}{|c|}{ Varieties of Democracy } & \multicolumn{5}{|c|}{ Democracy Barometer } \\
\hline & Prim. & Sec. & Tert. & Sec.-Prim. & Tert.-Prim. & Prim. & Sec. & Tert. & Sec.-Prim. & Tert.-Prim. \\
\hline \multicolumn{11}{|c|}{ Trust $\rightarrow$ Democracy } \\
\hline 1 & 0.53 & 0.52 & 0.52 & 0.47 & 0.48 & 0.90 & 0.85 & 0.79 & 0.27 & 0.17 \\
\hline 2 & 0.68 & 0.67 & 0.65 & 0.42 & 0.36 & 0.85 & 0.75 & 0.74 & 0.13 & 0.16 \\
\hline 3 & 0.58 & 0.57 & 0.54 & 0.47 & 0.35 & 0.77 & 0.68 & 0.64 & 0.21 & 0.18 \\
\hline 4 & 0.58 & 0.59 & 0.53 & 0.55 & 0.29 & 0.91 & 0.83 & 0.77 & 0.11 & 0.08 \\
\hline 5 & 0.46 & 0.50 & 0.44 & 0.74 & 0.40 & 0.97 & 0.93 & 0.90 & 0.16 & 0.11 \\
\hline \multicolumn{11}{|c|}{ Democracy $\rightarrow$ Trust } \\
\hline 1 & 0.67 & 0.83 & 0.89 & 0.98 & $>0.99$ & 0.87 & 0.91 & 0.95 & 0.85 & 0.96 \\
\hline 2 & 0.82 & 0.92 & 0.95 & 0.99 & $>0.99$ & 0.73 & 0.85 & 0.88 & 0.97 & 0.94 \\
\hline 3 & 0.48 & 0.67 & 0.82 & 0.98 & $>0.99$ & 0.80 & 0.90 & 0.91 & 0.95 & 0.93 \\
\hline 4 & 0.35 & 0.56 & 0.78 & 0.98 & $>0.99$ & 0.85 & 0.92 & 0.93 & 0.93 & 0.88 \\
\hline 5 & 0.19 & 0.37 & 0.62 & 0.97 & $>0.99$ & 0.90 & 0.95 & 0.95 & 0.92 & 0.80 \\
\hline
\end{tabular}

Note: Prim. = Primary or incomplete secondary education; Sec. = Secondary or post-secondary non-tertiary education, Tert. = Tertiary education. Results are based on the same models as shown in Figure 3.

$\beta=0.02, \mathrm{CI}=[-0.01,0.04]$, to $\beta=0.05, \mathrm{CI}=[-0.02,0.12]$, for secondary, and from $\beta=0.04, \mathrm{CI}=[-0.00$, $0.08]$, to $\beta=0.06, \mathrm{CI}=[-0.04,0.16]$, for tertiary education.

Posterior probabilities of the effect of democracy on trust being greater for people with secondary or tertiary education compared to those with primary education are very high (see Table 2, columns Tert.-Prim. and Sec.-Prim. corresponding to models using both democracy indicators), exceeding 0.95 in models with the V-Dem index, and ranging between 0.8 and 0.97 in models with the DB index of democracy. By-country effects in Figures 8 and 10 in Appendix 2 show that the positive coefficients are present in virtually all countries. Models with the DB index of democracy point in the same direction but with comparatively more uncertainty.

Taken together, these results provide support for Hypothesis 3, which stated that democracy is a stronger predictor of political trust among people with higher levels of education than among those with less education. At the same time, we found no evidence for the expected differences in the effect of political trust among people with different education attainment on democracy (Hypothesis 4). On the contrary, we found that at least based on models with the DB index - the probabilities of positive effects of trust on democracy are lower, not higher, for people with tertiary education compared to those with primary education, which is the exact opposite of what we expected.

\subsection{Political trust by age group}

\subsubsection{Effects of trust on democracy}

The last part of the analysis deals with the differences in the effect of political trust exhibited by people of different ages on democracy, and the differences in the effect of democracy on trust among different age groups. Figure 4 presents the relevant interaction coefficients for the two older age groups - 35-54 and 55-74 - with the youngest age group, 20-34, as the reference category. Coefficients for the effects of trust on democracy in the upper part of Figure 4 are all very small and are accompanied by relatively high uncertainty. The same applies to by-country effects presented in Figures 11 and 13 in Appendix 3. While in models with the DB index the interaction coefficients are slightly higher than in models with the V-Dem indicator, even there 
the probabilities of differences in the effects by age group are small (cf. Table 3, where the probabilities in columns (35-54) - (20-34) and (55-74) - (20-34) in the upper part of the table are all relatively close to 0.5).
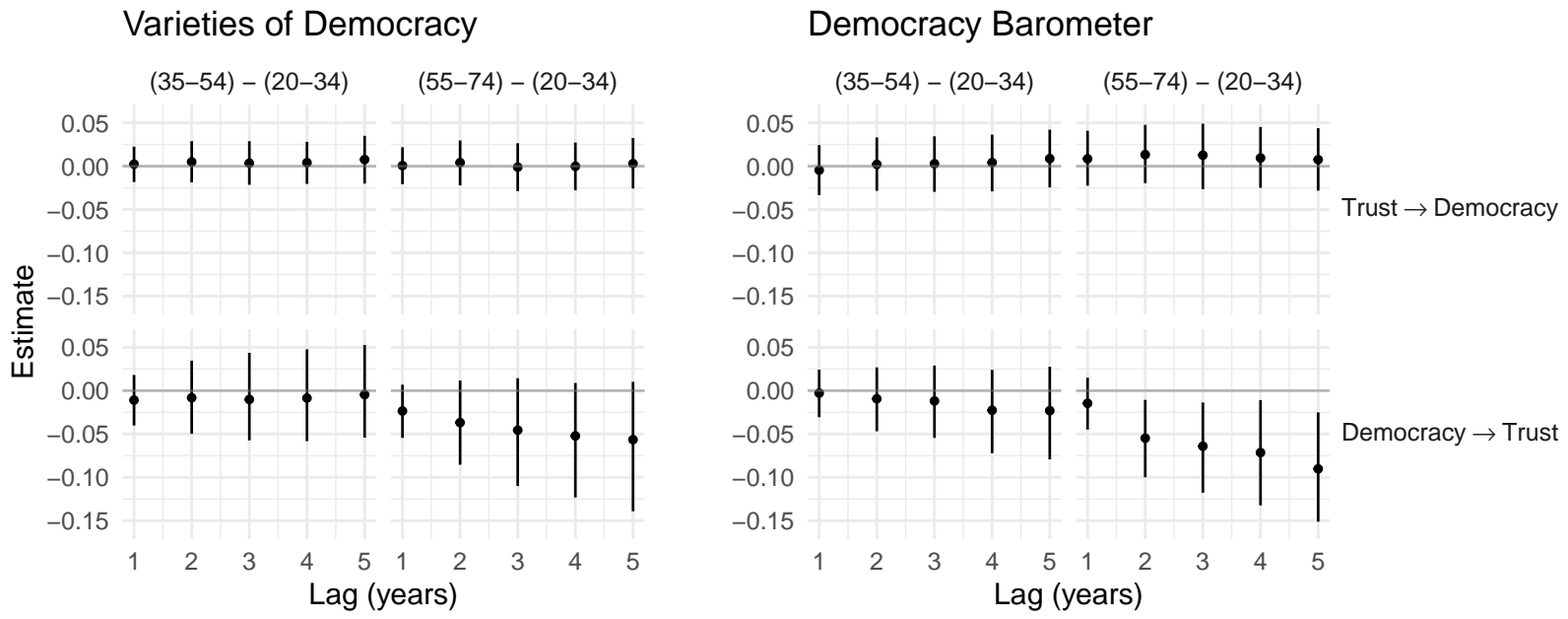

Figure 4: Interaction effect estimates of democracy on political trust and vice versa, for age groups 35-54 and 55-74 with the age group 20-34 as the reference category, for different lag lengths. Models use the Varieties of Democracy and Democracy Barometer indicators. Points indicate posterior means and error bars indicate $95 \%$ credible intervals..

\subsubsection{Effects of democracy on trust}

The lower part of Figure 4 shows interaction effects of democracy on trust in the middle (35-54) and oldest (55-74) age groups with the youngest (20-34) age groups as the reference category, indicating little difference between the youngest and middle age groups in both sets of models, with either of the two democracy indicators. At the same time, both sets of models suggest a more negative effect of democracy on trust among the oldest age group compared to the youth. In the models with the V-dem democracy index, the interaction coefficient ranges from $\beta=-0.02, \mathrm{CI}=[-0.05,0.01]$, for the one-year lag to $\beta=-0.06, \mathrm{CI}=[-0.14,0.01]$, for the five-year lag. In models with the DB index, the coefficients for the one-year lag are minimal, and then range between $\beta=-0.05, \mathrm{CI}=[-0.10,-0.01]$, for the two-year lag and $\beta=-0.09$, $\mathrm{CI}=[-0.15,-0.03]$, for the five-year lag. Consistently, Figures 12 and 14 point to more systematically negative effects in models with the DB than in the $\mathrm{V}$-Dem index.

According to posterior probabilities of positive effects in Table 3, the probability that the effect of democracy on trust among the oldest age group is smaller than the same effect among the youngest age group exceeds 0.9 (complements of probabilities in columns with the headers (55-74) - (20-34) in the lower panel of Table 3 ), for all models with the exception of the model with the DB indicator and one-year lag.

Based on these results, we find no support for the claim that political trust among the youth has a weaker effect on democracy than political trust among older adults, as stated in Hypothesis 5. At the same time, we find evidence of variation in the effects of democracy on political trust among different age groups, in that democracy is less positively predictive of political trust among the oldest age group compared to the youngest and middle age groups. 
Table 3: Posterior probabilities of the effects being positive, by education level.

\begin{tabular}{|c|c|c|c|c|c|c|c|c|c|c|}
\hline \multirow[b]{2}{*}{ Lag } & \multicolumn{5}{|c|}{ Varieties of Democracy } & \multicolumn{5}{|c|}{ Democracy Barometer } \\
\hline & $20-34$ & $35-54$ & $55-74$ & $\begin{array}{l}(35-54)- \\
(20-34)\end{array}$ & $\begin{array}{l}(55-74)- \\
(20-34)\end{array}$ & $20-34$ & $35-54$ & $55-74$ & $\begin{array}{l}(35-54)- \\
(20-34)\end{array}$ & $\begin{array}{l}(55-74)- \\
(20-34)\end{array}$ \\
\hline \multicolumn{11}{|c|}{ Trust $\rightarrow$ Democracy } \\
\hline 1 & 0.34 & 0.36 & 0.34 & 0.59 & 0.52 & 0.86 & 0.84 & 0.87 & 0.37 & 0.70 \\
\hline 2 & 0.57 & 0.59 & 0.59 & 0.66 & 0.63 & 0.75 & 0.76 & 0.79 & 0.56 & 0.79 \\
\hline 3 & 0.54 & 0.56 & 0.54 & 0.61 & 0.46 & 0.74 & 0.74 & 0.77 & 0.57 & 0.75 \\
\hline 4 & 0.61 & 0.63 & 0.61 & 0.63 & 0.50 & 0.84 & 0.85 & 0.86 & 0.60 & 0.70 \\
\hline 5 & 0.48 & 0.50 & 0.48 & 0.71 & 0.58 & 0.92 & 0.93 & 0.93 & 0.70 & 0.65 \\
\hline \multicolumn{11}{|c|}{ Democracy $\rightarrow$ Trust } \\
\hline 1 & 0.73 & 0.68 & 0.62 & 0.22 & 0.06 & 0.82 & 0.81 & 0.77 & 0.42 & 0.17 \\
\hline 2 & 0.86 & 0.85 & 0.80 & 0.34 & 0.06 & 0.80 & 0.77 & 0.61 & 0.31 & 0.01 \\
\hline 3 & 0.64 & 0.62 & 0.53 & 0.33 & 0.07 & 0.85 & 0.83 & 0.72 & 0.29 & 0.01 \\
\hline 4 & 0.53 & 0.51 & 0.38 & 0.35 & 0.05 & 0.88 & 0.85 & 0.77 & 0.18 & 0.01 \\
\hline 5 & 0.36 & 0.34 & 0.21 & 0.41 & 0.05 & 0.95 & 0.93 & 0.84 & 0.19 & 0.01 \\
\hline
\end{tabular}

Note: Results are based on the same models as shown in Figure 4.

\section{Conclusion}

Social science research on political trust often assumes that trust in the state and its institutions among the population is necessary for democracy to thrive, and that democracy in turn contributes to strengthening political trust. We examined these propositions with cross-lagged models of country time series of political trust - estimated from 13 cross-national survey projects - and democracy indicators from two recognized sources, the Varieties of Democracy and the Democracy Barometer datasets, from 26 European countries between 1991 and 2019 .

We find evidence of an effect of political trust on democracy for all five lag lengths, and with coefficients increasing for longer lag lengths, but only in models using the democracy index from the Democracy Barometer project. As new surveys in the coming years extend the time series, models with longer lags will show whether the tendency continues to hold. Models with the V-Dem indicator only showed a positive effect for one-year lags, which suggest a cross-national rather than longitudinal association.

The effects of democracy on trust depend on the choice of the democracy index as well. The effects are positive with consistent magnitude for all lag lengths in models using the DB index, but in models with the V-Dem index only models with one- and two-year lags point to a positive effect, and the coefficients drop sharply for longer lags. The variation in the direction and magnitude of by-country effects of trust on democracy and democracy on trust points to considerable between-country heterogeneity, whose exploration may constitute a fruitful avenue for future research.

When looking across societal groups, we find evidence of differences in the effect of democracy on political trust among people with different levels of education and of different ages. Our results suggest that people with more education are more sensitive to changes in democracy, which matches our expectation derived from the fact that higher education is associated with more democratic orientations and higher levels of political knowledge and competence. Differences in the effects of democracy on trust by age suggest a more negative association among the oldest respondents compared to young adults. Instead of indicating the distinctively high sensitivity to democratic performance of the youth, these results point to the lower sensitivity among the oldest respondents, which is a different contrast that we had hypothesized about. Nevertheless, the results point to differences that are worthy of further exploration, also taking into account cohorts instead of or in 
addition to age groups.

At the same time, we find no evidence of differences in the effects of trust among education and age groups on democracy in the expected directions. Even though these groups differ with regard to political engagement, political interests, and the amount of resources at their disposal, there is little evidence that their attitudes exert a different effect on the quality of democracy, at least not over the short time spans our analysis covered. If anything, models with the DB index weakly suggest that posterior probabilities of positive effects of political trust among people with tertiary education on democracy are smaller than probabilities of positive effects of people with primary education on democracy. This result, if confirmed, would run against our theoretical expectations derived primarily from the resource approach to explaining political engagement.

Altogether, the results regarding the bi-directional lagged effects between political trust and democracy are rather weak, which could arguably be expected given the relatively simple models and the crude measures meant to represent a likely complex phenomenon. Theoretical debates have long recognized the multifaceted nature of political support by pointing to distrust and skepticism as the public's way of ensuring government accountability (Mishler and Rose, 1997; Wu and Wilkes, 2018). The consequence of this reasoning is the need to identify healthy distrust and unfounded trust, which unidimensional measures of political trust available in comparative surveys do not enable. Regarding modeling, as the time series of political attitudes available to researchers become longer, there will be more opportunities for modeling more complex associations. Analyzing data from other regions than Europe may prove more informative, as many European Union countries have seen relatively little variation in democracy in the recent decades.

The analytic framework we applied, combining model-based aggregation of survey data and poststratification with cross-lagged models accounting for errors in measurement, can be flexibly adapted and used for further investigations on the causes and consequences of mass attitudes. We emphasize the need to incorporate information about the uncertainty in measures on public opinion, and - ideally - also indicators of macro-level characteristics. Our results point to the importance of considering different reasonable alternatives both in model design and in the measurement of crucial variables. Analyses of the bi-directional effects between political trust and democracy using two democracy indicators and different lags show how sensitive the results are to these choices. We generally find that models with the DB democracy index are more consistent with the theoretical propositions about the overall effect of political trust on democracy, and it may be tempting to interpret these results in substantive terms to say that "objective" measures used by DB are more relevant than expert assessments that V-Dem relies on. We believe that before such statements can be made, it is necessary to devote more attention to the (in)consistency between governance indicators and their sources, as well as to exploring the different aspects of democracy and governance that are more or less strongly associated with changes in political trust. 


\section{Appendices}

\subsection{Appendix 1: By-country results, overall}

\subsubsection{Varieties of Democracy}
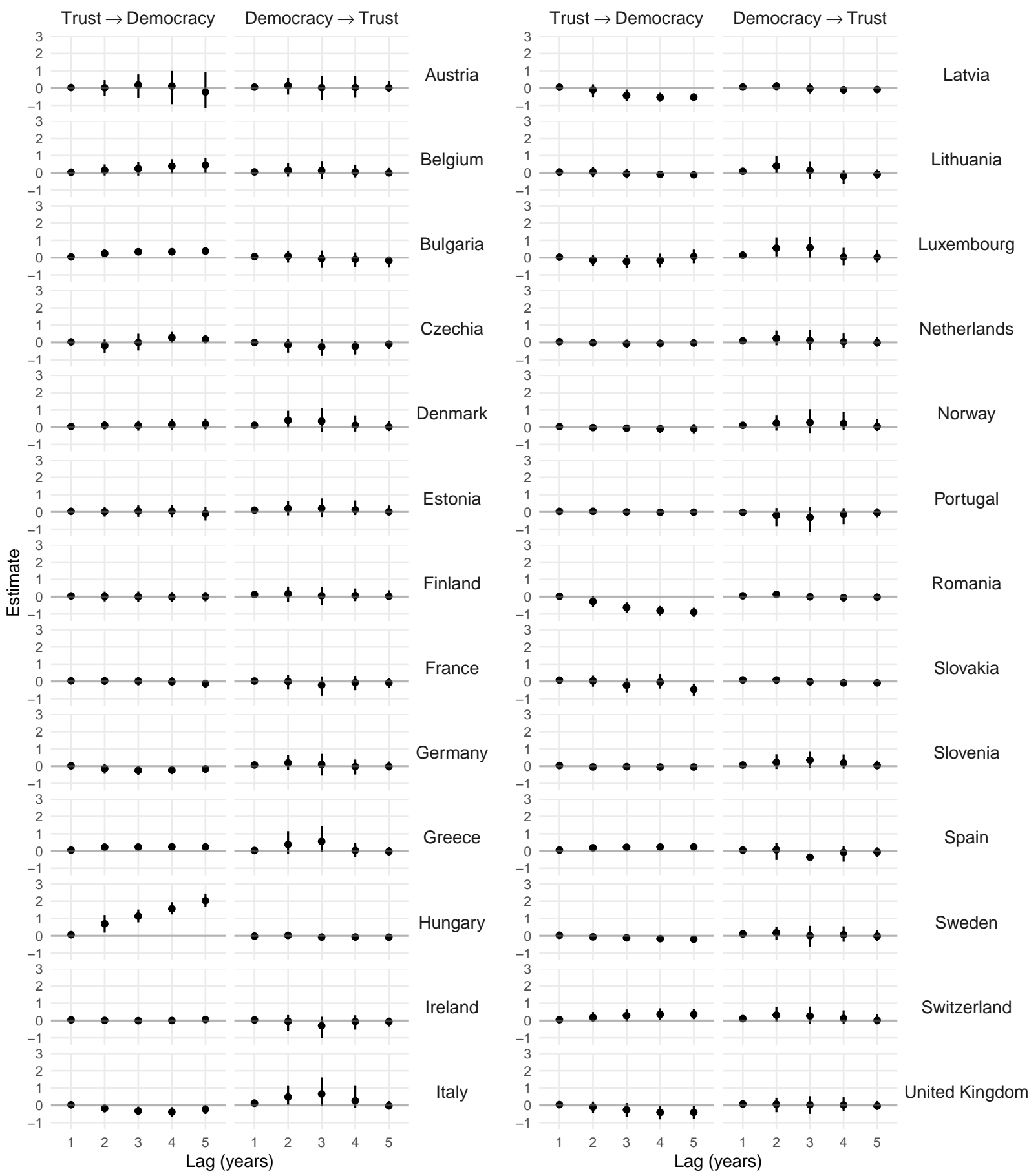

Figure 5: By-country effect estimates of democracy on political trust and vice versa from models with the Varieties of Democracy indicator for different lag lengths. Points indicate posterior means and error bars indicate $95 \%$ credible intervals. 


\subsubsection{Democracy Barometer}
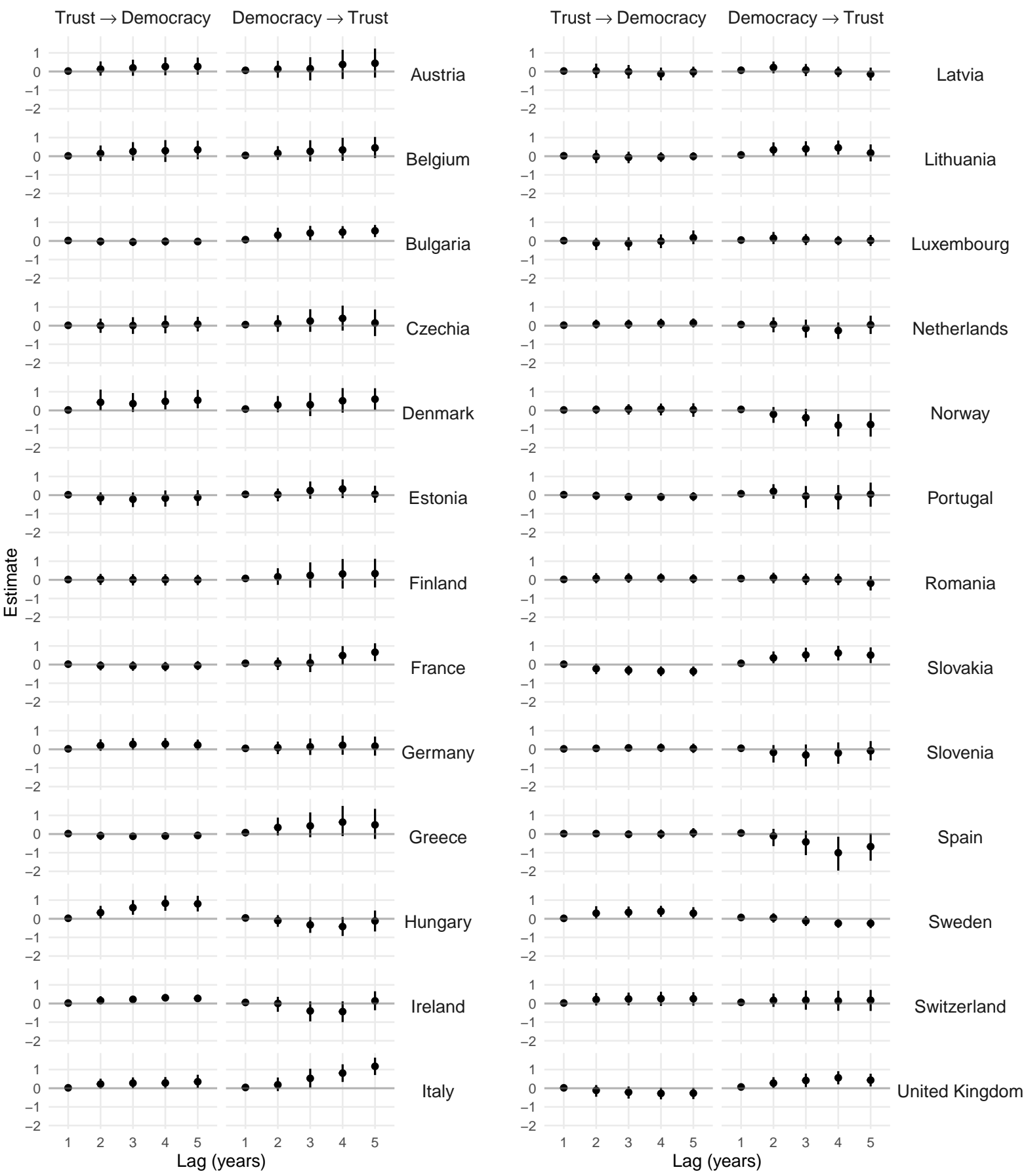

Figure 6: By-country effect estimates of democracy on political trust and vice versa from models with the Democracy Barometer indicator for different lag lengths. Points indicate posterior means and error bars indicate $95 \%$ credible intervals. 


\subsection{Appendix 2: By-country results, by education}

\subsubsection{Varieties of Democracy: Trust $\rightarrow$ Democracy}
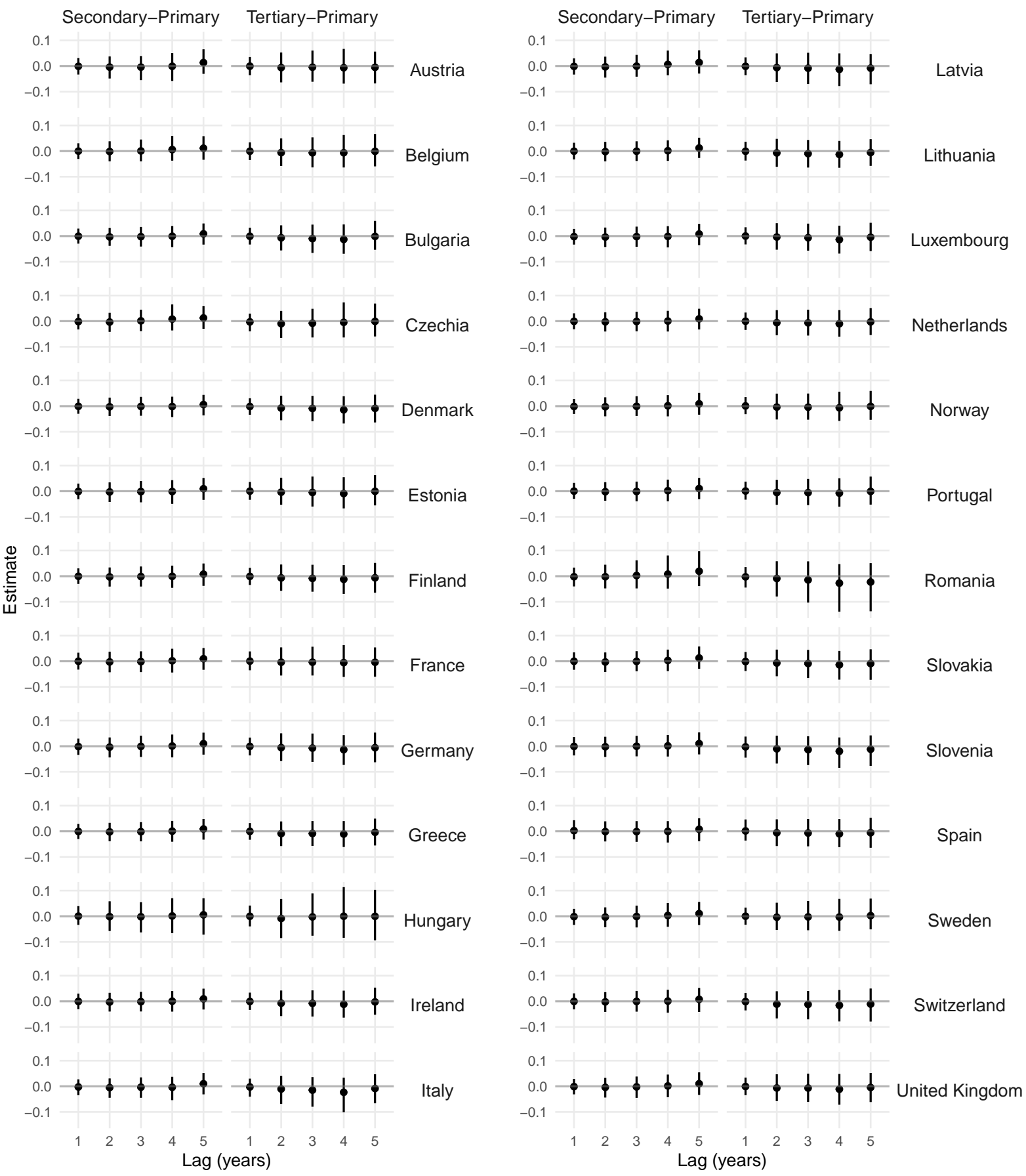

Figure 7: By-country interaction effect estimates of political trust on democracy, for secondary and tertiary education with primary education as the reference category, for different lag lengths. Models use the Varieties of Democracy indicator. Points indicate posterior means and error bars indicate $95 \%$ credible intervals. 


\subsubsection{Varieties of Democracy: Democracy $\rightarrow$ Trust}
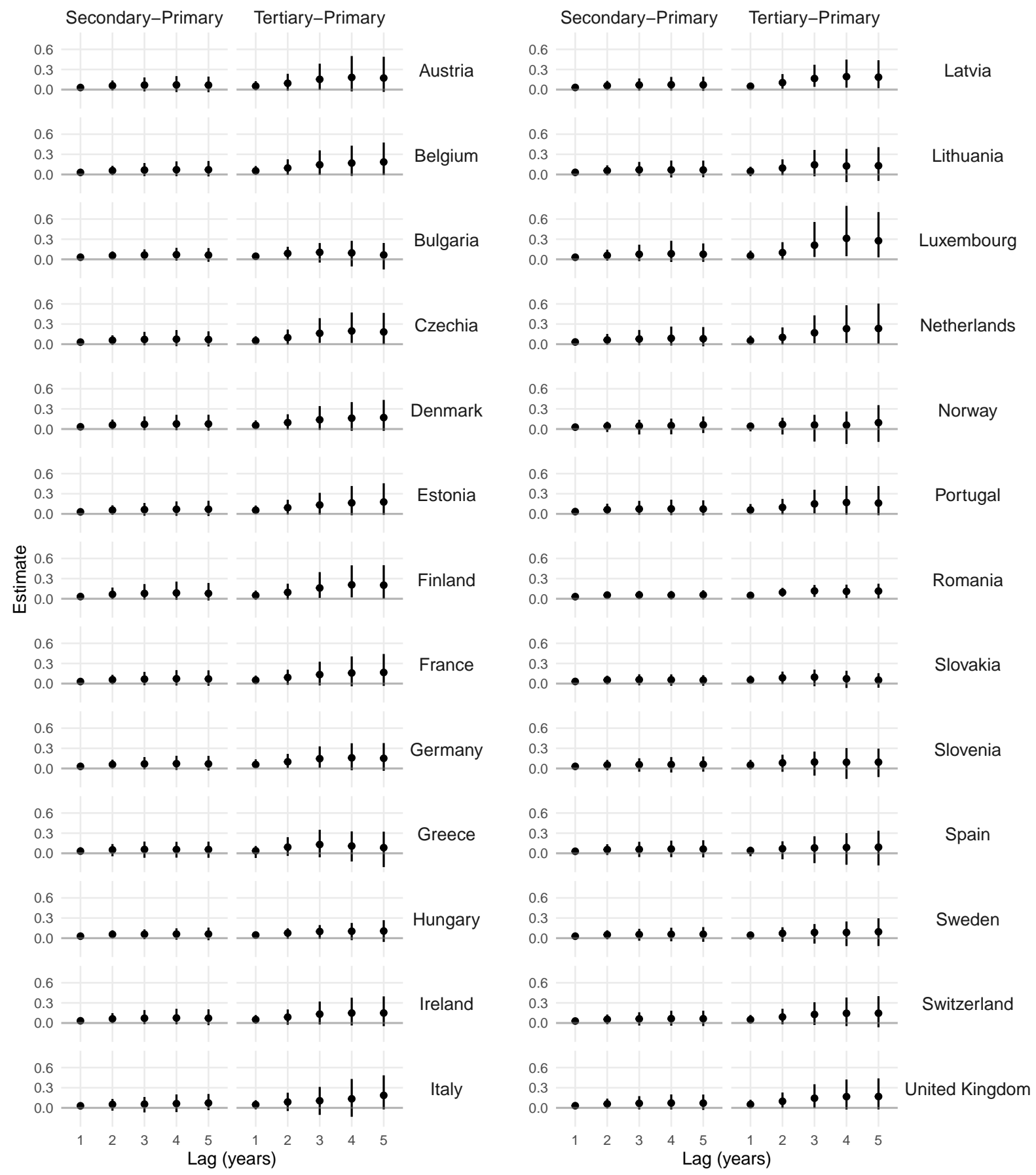

Figure 8: By-country interaction effect estimates of democracy on political trust, for secondary and tertiary education with primary education as the reference category, for different lag lengths. Models use the Varieties of Democracy indicator. Points indicate posterior means and error bars indicate $95 \%$ credible intervals. 


\subsubsection{Democracy Barometer: Trust $\rightarrow$ Democracy}
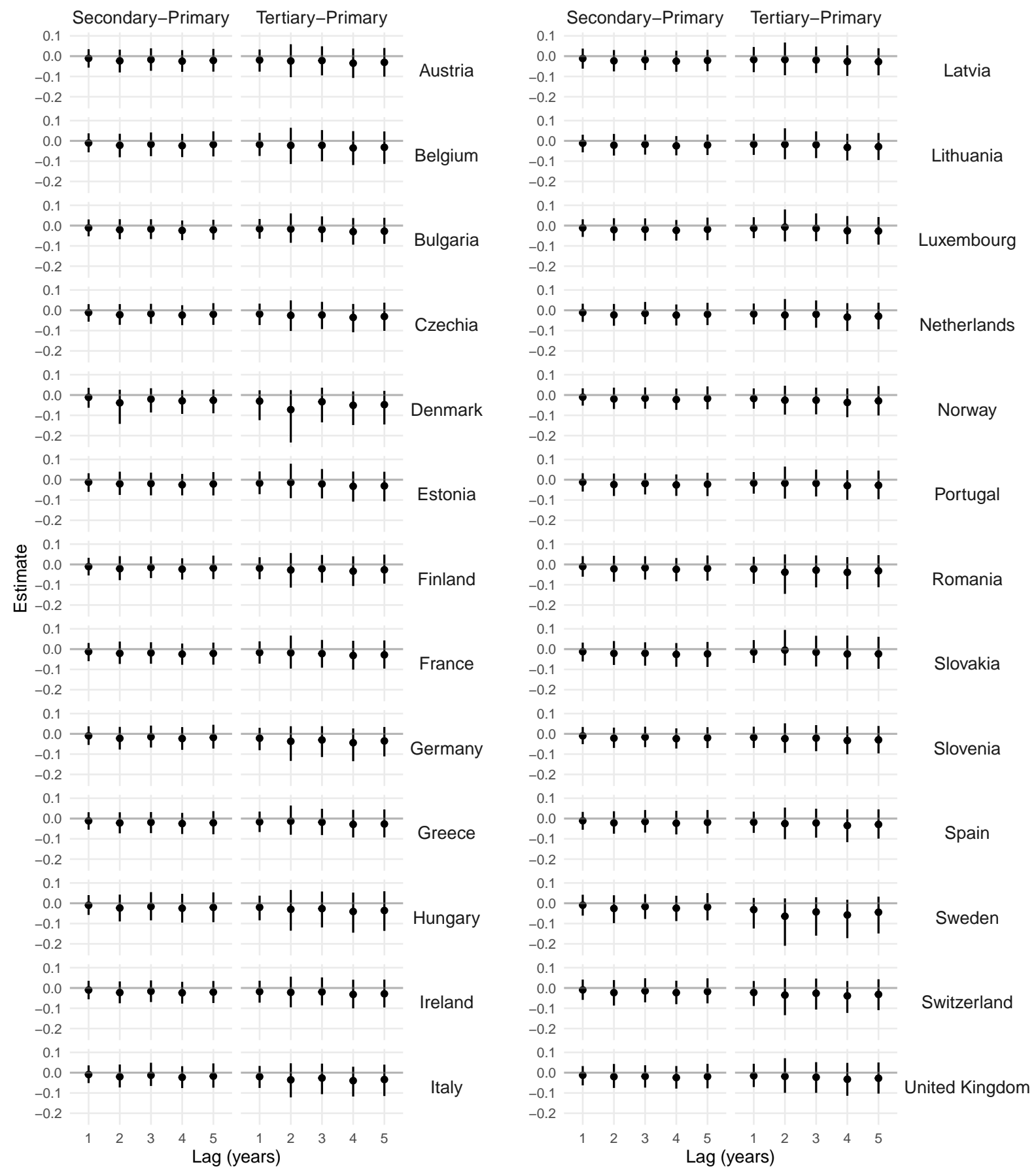

Figure 9: By-country interaction effect estimates of political trust on democracy, for secondary and tertiary education with primary education as the reference category, for different lag lengths. Models use the Democracy Barometer indicator. Points indicate posterior means and error bars indicate $95 \%$ credible intervals. 


\subsubsection{Democracy Barometer: Democracy $\rightarrow$ Trust}
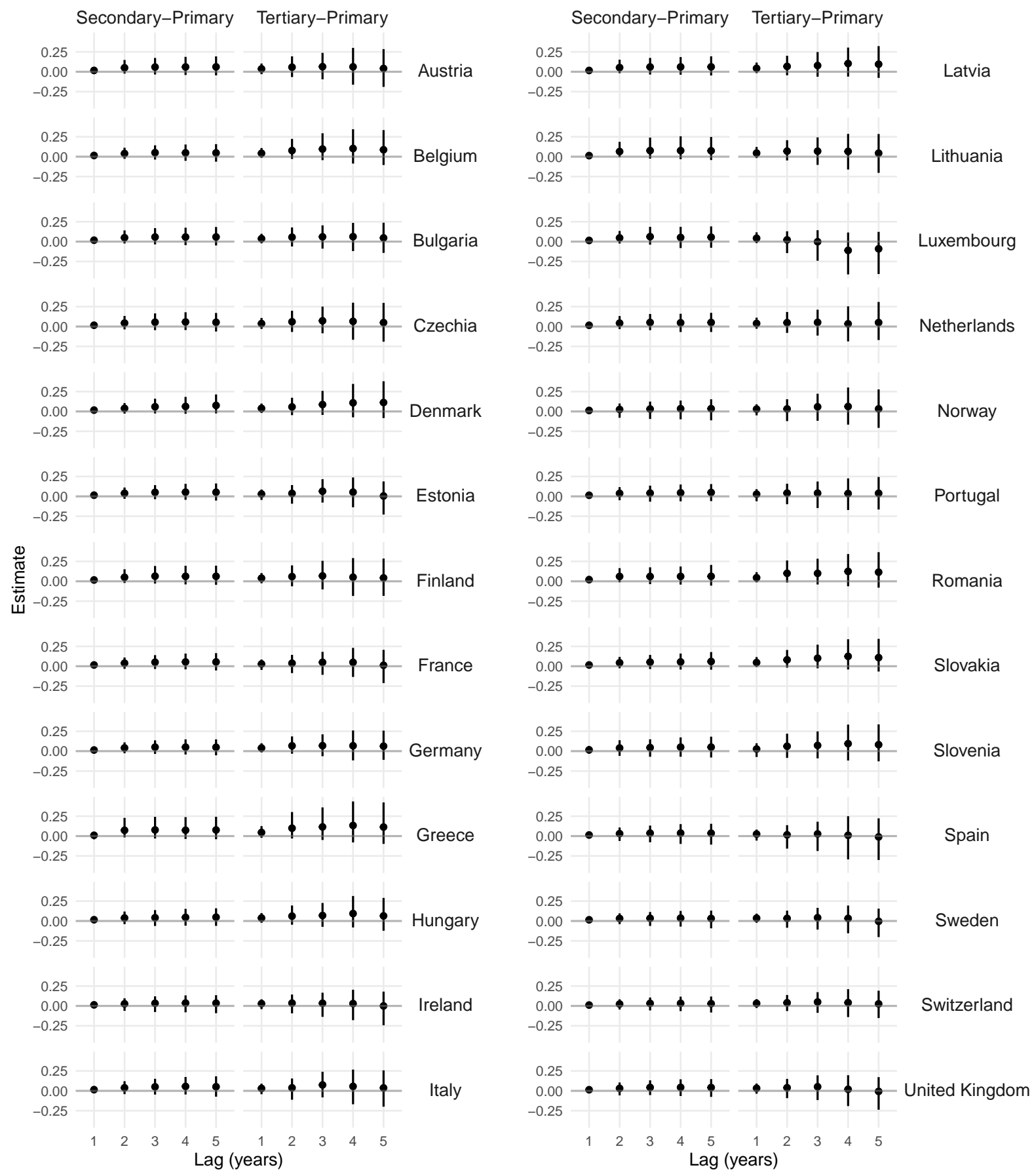

Figure 10: By-country interaction effect estimates of democracy on political trust, for secondary and tertiary education with primary education as the reference category, for different lag lengths. Models use the Democracy Barometer indicator. Points indicate posterior means and error bars indicate $95 \%$ credible intervals. 


\subsection{Appendix 3: By-country results, by age}

\subsubsection{Varieties of Democracy: Trust $\rightarrow$ Democracy}
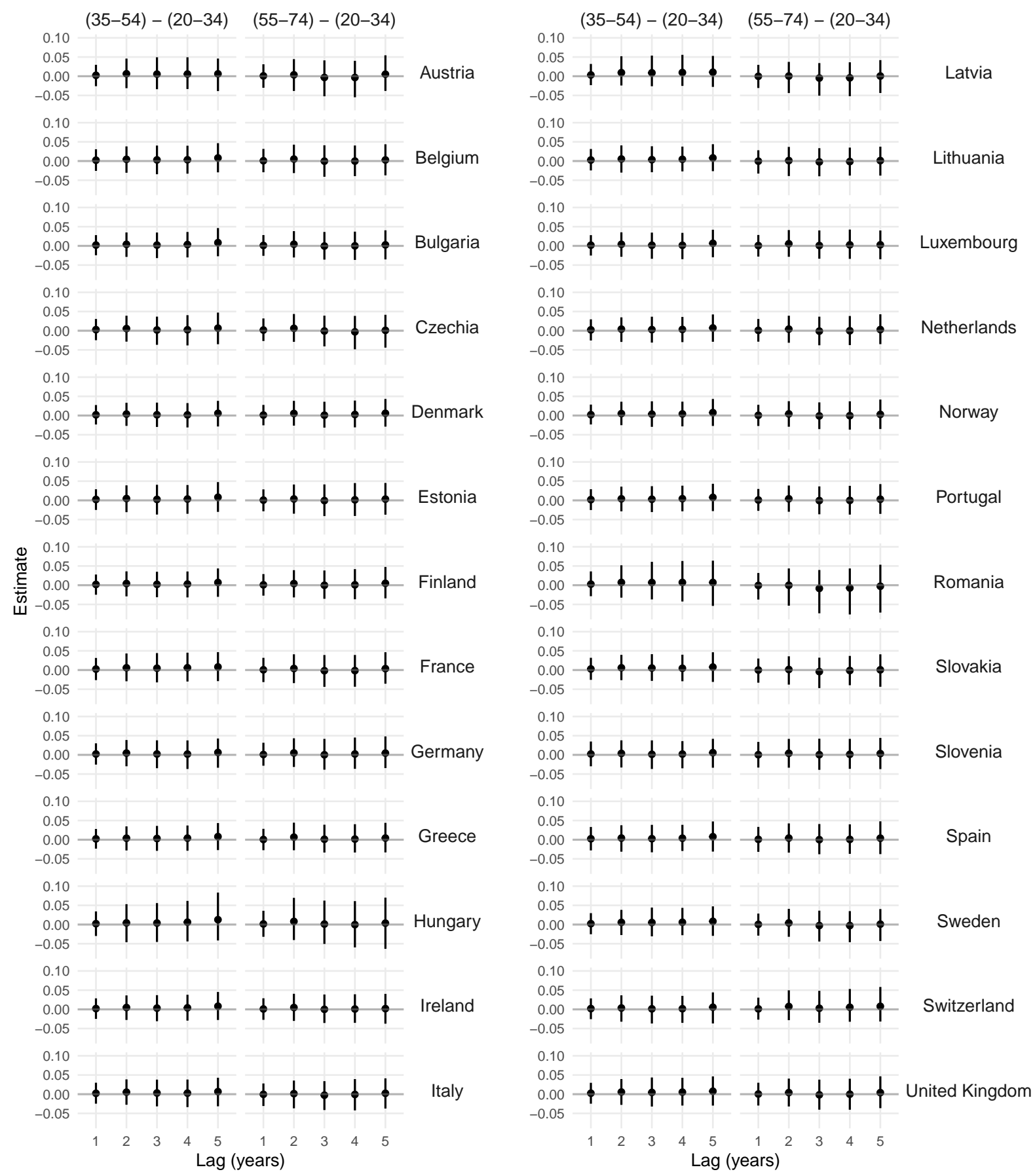

Figure 11: By-country interaction effect estimates of political trust on democracy, for age groups 35-54 and 55-74 with the age group 20-34 as the reference category, for different lag lengths. Models use the Varieties of Democracy indicator. Points indicate posterior means and error bars indicate $95 \%$ credible intervals. 
6.3.2 Varieties of Democracy: Democracy $\rightarrow$ Trust
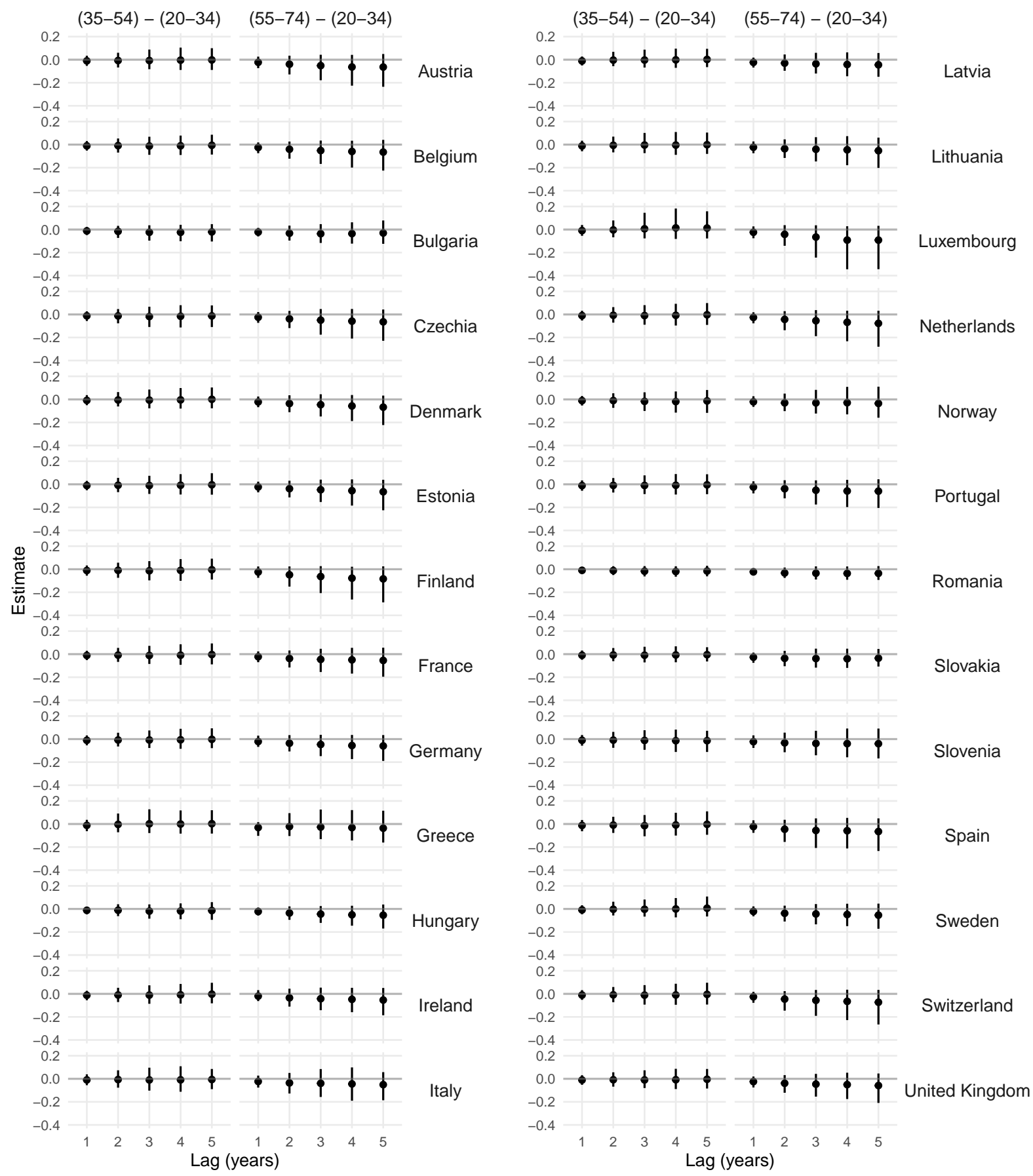

Figure 12: By-country interaction effect estimates of democracy on political trust, for age groups 35-54 and 55-74 with the age group 20-34 as the reference category, for different lag lengths. Models use the Varieties of Democracy indicator. Points indicate posterior means and error bars indicate $95 \%$ credible intervals. 


\subsubsection{Democracy Barometer: Trust $\rightarrow$ Democracy}

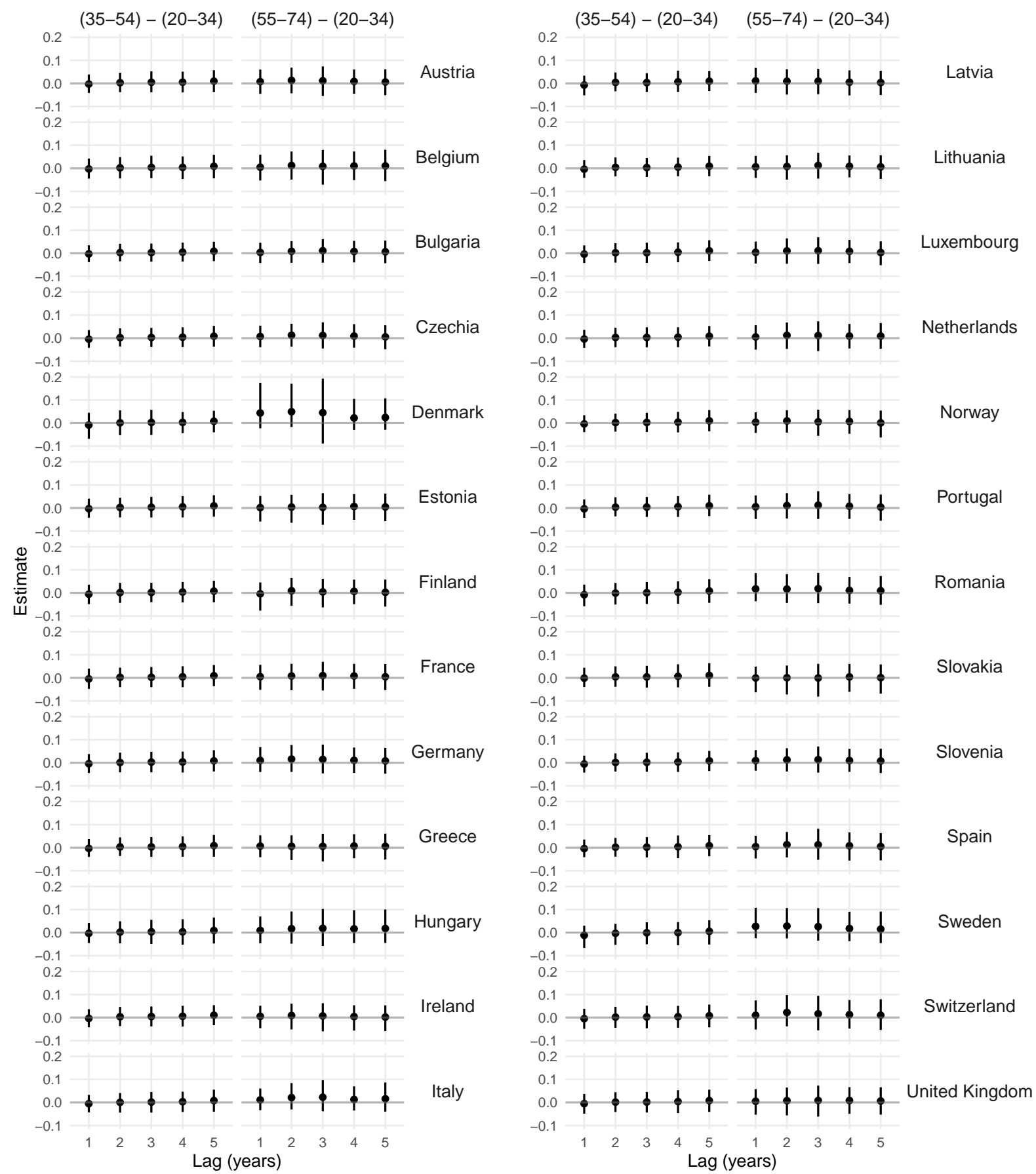

Figure 13: By-country interaction effect estimates of political trust on democracy, for age groups 35-54 and 55-74 with the age group 20-34 as the reference category, for different lag lengths. Models use the Democracy Barometer indicator. Points indicate posterior means and error bars indicate $95 \%$ credible intervals. 


\subsubsection{Democracy Barometer: Democracy $\rightarrow$ Trust}

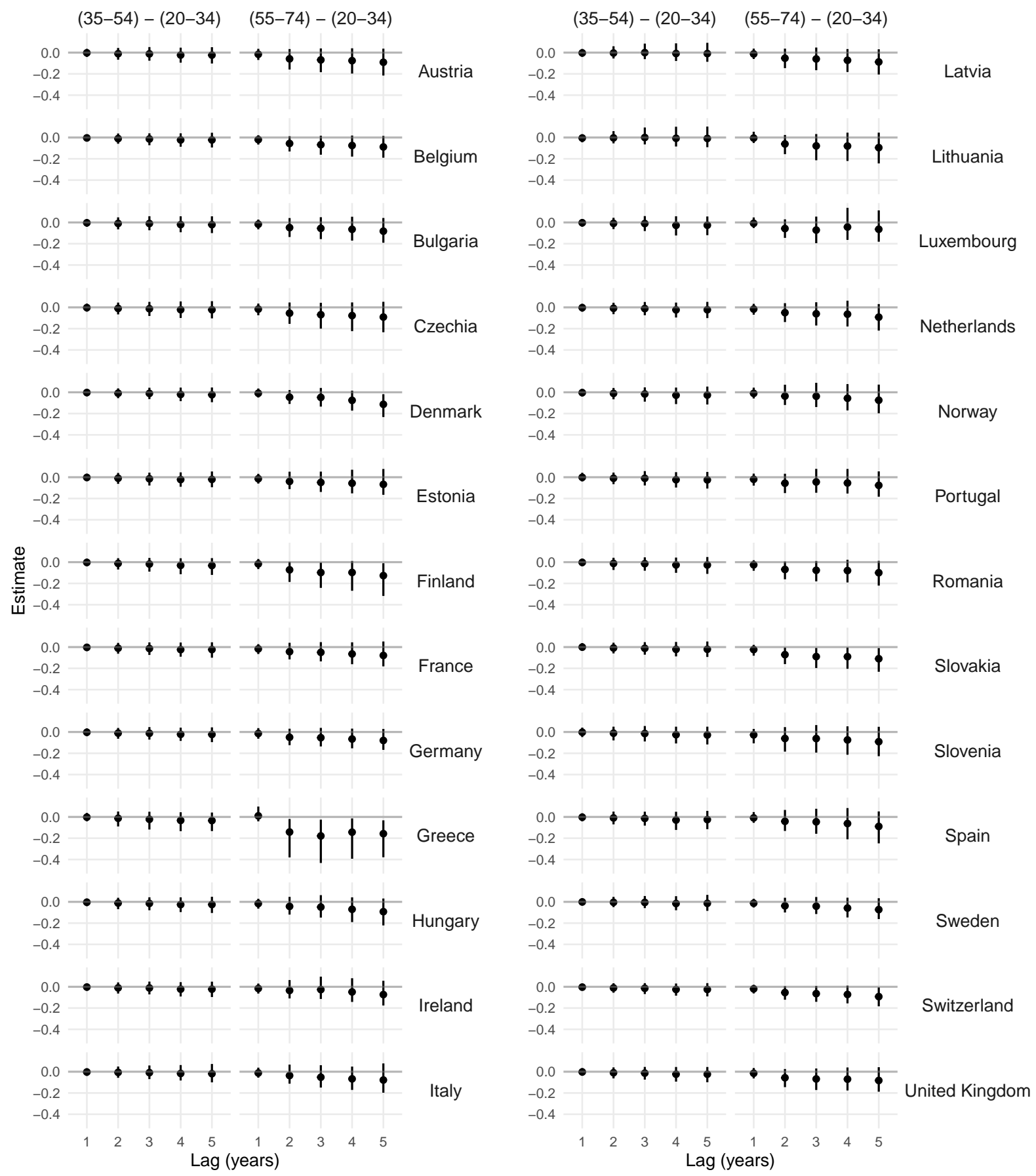

Figure 14: By-country interaction effect estimates of democracy on political trust, for age groups 35-54 and 55-74 with the age group 20-34 as the reference category, for different lag lengths. Models use the Democracy Barometer indicator. Points indicate posterior means and error bars indicate $95 \%$ credible intervals. 


\section{Replication materials}

Replication materials are available at: https://osf.io/chx6a/

\section{Acknowledgements}

The calculations were performed using computer resources within the Aalto University School of Science "Science-IT" project. The project was completed while Marta Kołczyńska was a visiting researcher at the Probabilistic Machine Learning Group, Department of Computer Science, Aalto University.

\section{$9 \quad$ Funding}

This research was supported by the Polish National Agency for Academic Exchange within the Bekker programme (award number BEK/2019/1/00133). 


\section{References}

Aars, J. and Strømsnes, K. (2007). Contacting as a Channel of Political Involvement: Collectively Motivated Individually Enacted. West European Politics, 30(1):93-120.

Alexander, A. C. and Welzel, C. (2017). The Myth of Deconsolidation: Rising Liberalism and the Populist Reaction. ILE Working Paper Series, 10. http://hdl.handle.net/10419/170694.

Almond, G. A. and Verba, S. (1963). The Civic Culture: Political Attitudes and Democracy in Five Nations. Princeton: Princeton University Press.

Bauer, P. C. (2018). Unemployment, Trust in Government, and Satisfaction with Democracy: An Empirical Investigation. Socius: Sociological Research for a Dynamic World, 4:237802311775053.

Blais, A., Gidengil, E., and Nevitte, N. (2004). Where does turnout decline come from? European Journal of Political Research, 43(2):221-236.

Bobo, L. and Licari, F. C. (1989). Education and Political Tolerance: Testing the Effects of Cognitive Sophistication and Target Group Affect. Public Opinion Quarterly, 53(3):285.

Botero, J., Ponce, A., and Shleifer, A. (2012). Education and the Quality of Government. NBER Working Paper Series, (18119).

Bürkner, P.-C. (2017). brms : An R Package for Bayesian Multilevel Models Using Stan. Journal of Statistical Software, 80(1).

Carpenter, B., Gelman, A., Hoffman, M. D., Lee, D., Goodrich, B., Betancourt, M., Brubaker, M., Guo, J., Li, P., and Riddell, A. (2017). Stan: A Probabilistic Programming Language. Journal of Statistical Software, 76(1).

Chong, A. and Gradstein, M. (2015). On Education and Democratic Preferences. Economics and Politics, $27(3): 362-388$.

Clarke, H. D., Dutt, N., and Kornberg, A. (1993). The Political Economy of Attitudes toward Polity and Society in Western European Democracies. The Journal of Politics, 55(4):998-1021.

Coppedge, M., Gerring, J., Knutsen, C. H., Lindberg, S. I., Teorell, J., Altman, D., Bernhard, M., Fish, M. S., Glynn, A., Hicken, A., Lührmann, A., Marquardt, K. L., McMann, K., Paxton, P., Pemstein, D., Seim, B., Sigman, R., Skaaning, S.-E., Staton, J., Cornell, A., Gastaldi, L., Gjerløw, H., Mechkova, V., von Römer, J., Sundtröm, A., Tzelgov, E., Uberti, L., Wang, Y.-t., Wig Tore, and Ziblatt, D. (2020). V-Dem Codebook v10.

Cornelis, I. and Van Hiel, A. (2015). Extreme-Right Voting in Western Europe: The Role of Social-Cultural and Antiegalitarian Attitudes. Political Psychology, 36(6):749-760.

Dalton, R. J. (2004). Democratic Challenges, Democratic Choices: The Erosion of Political Support in Advanced Industrial Democracies. Oxford: Oxford University Press.

Dalton, R. J., Van Sickle, A., Weldon, S., Sickle, A. V., and Weldon, S. (2010). The individual-institutional nexus of protest behaviour. British Journal of Political Science, 40(1):51-73.

Devine, D., Gaskell, J., Jennings, W., and Stoker, G. (2020). Trust and the Coronavirus Pandemic: What are the Consequences of and for Trust? An Early Review of the Literature. Political Studies Review, 00:1-12. 
Easton, D. (1965). A Systems Analysis of Political Life. New York: Wiley.

Easton, D. (1975). A Re-assessment of the Concept of Political Support. British Journal of Political Science, $5(4): 435-457$.

Edwards, J. R. (1994). Regression analysis as an alternative to difference scores. Journal of Management, 20(3):683-689.

Engler, S., Leemann, L., Abou-Chadi, T., Gieber, H., Bousbah, K., Bochsler, D., Hänni, M., Heyne, L., Juon, A., Merkel, W., Müller, L., Ruth, S., and Wessels, B. (2020). Democracy Barometer. Codebook. Version 7. Technical report.

European Social Survey (2020). European Social Survey Cumulative File, ESS 1-9 (2020).

Eurostat (2020). Unemployment by sex and age - monthly data: une_rt_m. https://ec.europa.eu/eurostat/en/web/products-datasets/-/UNE_RT_M.

Ezeibe, C. C., Ilo, C., Ezeibe, E. N., Oguonu, C. N., Nwankwo, N. A., Ajaero, C. K., and Osadebe, N. (2020). Political distrust and the spread of COVID-19 in Nigeria. Global Public Health, 0(0):1-14.

Foa, R. S. and Mounk, Y. (2016). The Democratic Disconnect. Journal of Democracy, 27(3):5-17.

Foa, R. S. and Mounk, Y. (2017). The Signs of Deconsolidation. Journal of Democracy, 28(1):5-15.

Franklin, M. and Riera, P. (2016). Types of Liberal Democracy and Generational Shifts. In How Europeans View and Evaluate Democracy, pages 111-129. Oxford University Press.

Gelman, A., Carlin, J. B., Stern, H. S., Dunson, D. B., Vehtari, A., and Rubin, D. B. (2013). Bayesian data analysis. CRC press.

Gelman, A., Jakulin, A., Pittau, M. G., Su, Y.-S., et al. (2008). A weakly informative default prior distribution for logistic and other regression models. The annals of applied statistics, 2(4):1360-1383.

Hakhverdian, A. and Mayne, Q. (2012). Institutional Trust, Education, and Corruption: A Micro-Macro Interactive Approach. The Journal of Politics, 74(3):739-750.

Hooghe, M. and Marien, S. (2013). A Comparative Analysis of the Relation between Political Trust and Forms of Political Participation in Europe. European Societies, 15(1):131-152.

Hough, M., Jackson, J., Bradford, B., Myhill, A., and Quinton, P. (2010). Procedural Justice, Trust, and Institutional Legitimacy. Policing, 4(3):203-210.

Hyman, H. and Wright, C. R. (1979). Education's Lasting Influence on Values. Chicago: University of Chicago Press.

Kołczyńska, M. (2020). Democratic values, education, and political trust. International Journal of Comparative Sociology, 61(1):1-24.

Kołczyńska, M. and Bürkner, P.-C. (2020). Marketplace of indicators: Inconsistencies between country trends of measures of governance. SocArXiv. https://osf.io/preprints/socarxiv/u8gsc/.

Kolczynska, M., Bürkner, P.-C., Kennedy, L., and Vehtari, A. (2020). Trust in state institutions in europe, 1989-2019. osf.io/preprints/socarxiv/3v5g7. 
Kwak, J., Tomescu-Dubrow, I., Slomczynski, K. M., and Dubrow, J. K. (2020). Youth, Institutional Trust, and Democratic Backsliding. American Behavioral Scientist, 64(9):1366-1390.

Letki, N. (2007). Institutional Performance. In Bevir, M., editor, Encyclopedia of Governance Vol. 1, pages 457-458. SAGE Publications, Inc.

Levi, M. and Stoker, L. (2000). Political Trust and Trustworthiness. Annual Review of Political Science, $3(1): 475-507$.

Lipset, S. M. (1983). Political Man: The Social Bases of Politics. Heinemann, London.

Lubbers, M., Gijsberts, M., and Scheepers, P. (2002). Extreme right-wing voting in Western Europe. European Journal of Political Research, 41(3):345-378.

Lussier, D. N. (2016). Political Trust and Regime Legitimacy. In Constraining Elites in Russia and Indonesia. Political Participation and Regime Survival, pages 232-263. Cambridge University Press.

Martin, P. S. and Claibourn, M. P. (2013). Citizen Participation and Congressional Responsiveness: New Evidence that Participation Matters. Legislative Studies Quarterly, 38(1):59-81.

Martini, S. and Quaranta, M. (2020). Citizens and Democracy in Europe. Contexts, Changes and Political Support. Palgrave Macmillan.

Mayne, Q. and Hakhverdian, A. (2017). Education, socialization, and political trust. In Zmerli, S. and van der Meer, T. W., editors, Handbook on Political Trust, pages 176-196. Edward Elgar Publishing.

McClosky, H. and Zaller, J. (1984). The American Ethos: Public Attitudes Toward Capitalism and Democracy. Cambridge: Harvard University Press.

Meyer, D. S. and Tarrow, S. (1998). The Social Movement Society: Contentious Politics for a New Century. Lanham: Rowman \& Littlefield Publishers.

Milligan, K., Moretti, E., and Oreopoulos, P. (2004). Does education improve citizenship? Evidence from the United States and the United Kingdom. Journal of Public Economics, 88(9-10):1667-1695.

Mishler, W. and Rose, R. (1997). Trust, Distrust and Skepticism: Popular Evaluations of Civil and Political Institutions in Post-Communist Societies. The Journal of Politics, 59(2):418-451.

Newton, K. and Montero, J. R. (2007). Patterns of Political and Social Participation in Europe. In Jowell, R., Roberts, C., Fitzgerald, R., and Eva, G., editors, Measuring Attitudes Cross-Nationally, pages 204-237. SAGE Publications, Ltd, London.

Norris, P. (1999). Introduction: The Growth of Critical Citizens? In Pippa Norris, editor, Critical Citizens: Global Support for Democratic Government, pages 1-28. Oxford University Press.

Norris, P. (2002). Democratic Phoenix: Reinventing Political Activism. Cambridge: Cambridge University Press.

Norris, P. (2011). Democratic Deficit: Critical Citizens Revisited. Cambridge University Press.

Norris, P. and Inglehart, R. (2019). Cultural Backlash. Trump, Brexit, and Authoritarian Populism. Cambridge University Press. 
Obydenkova, A. V. and Arpino, B. (2018). Corruption and Trust in the European Union and National Institutions: Changes over the Great Recession across European States. JCMS: Journal of Common Market Studies, 56(3):594-611.

Plutzer, E. (2002). Becoming a Habitual Voter: Inertia, Resources, and Growth in Young Adulthood. American Political Science Review, 96(1):41-56.

Putnam, R. (2000). Bowling Alone: The Collapse and Revival of American Community. New York: Simon \& Schuster.

Quintelier, E. (2007). Differences in political participation between young and old people. Contemporary Politics, 13(2):165-180.

Reilly, P. M. and Patino-Lea, H. (1981). A bayesian study of the error-in-variables model. Technometrics, 23(3):221-231.

Ruck, D. J., Matthews, L. J., Kyritsis, T., Atkinson, Q. D., and Bentley, R. A. (2020). The cultural foundations of modern democracies. Nature Human Behaviour, 4(3):265-269.

Schnaudt, C. (2019). Political Confidence and Democracy in Europe. Antecedents and Consequences of Citizens' Confidence in Representative and Regulative Institutions and Authorities. Springer.

Schuurman, N. K., Ferrer, E., de Boer-Sonnenschein, M., and Hamaker, E. L. (2016). How to compare cross-lagged associations in a multilevel autoregressive model. Psychological methods, 21(2):206.

Smets, K. (2016). Revisiting the political life-cycle model: later maturation and turnout decline among young adults. European Political Science Review, 8(2):225-249.

Smets, K. and van Ham, C. (2013). The embarrassment of riches? A meta-analysis of individual-level research on voter turnout. Electoral Studies, 32(2):344-359.

Sundström, A. and Stockemer, D. (2020). Conceptualizing, Measuring, and Explaining Youths' Relative Absence in Legislatures. PS: Political Science 83 Politics, pages 1-7.

Thomassen, J. and van Ham, C. (2017). A Legitimacy Crisis of Representative Democracy? In van Ham, C., Thomassen, J., Aarts, K., and Andeweg, R., editors, Myth and Reality of the Legitimacy Crisis: Explaining Trends and Cross-National Differences in Established Democracies, pages 3-16. Oxford University Press.

Tyler, T. R. (1990). Why People Obey the Law: Procedural Justice, Legitimacy, and Compliance. New Haven: Yale University Press.

Tyler, T. R. and Jackson, J. (2013). Future Challenges in the Study of Legitimacy and Criminal Justice. In Tankebe, J. and Liebling, A., editors, Legitimacy and criminal justice: An international exploration, pages 83-104. Oxford: Oxford University Press.

van der Meer, T. W. G. (2017). Political Trust and the "Crisis of Democracy". Oxford Research Encyclopedia of Politics, 1(March):1-25.

van Erkel, P. A. and van der Meer, T. W. (2016). Macroeconomic performance, political trust and the Great Recession: A multilevel analysis of the effects of within-country fluctuations in macroeconomic performance on political trust in 15 EU countries, 1999-2011. European Journal of Political Research, 55(1):177-197. 
van Kessel, S., Sajuria, J., and Van Hauwaert, S. M. (2020). Informed, uninformed or misinformed? A cross-national analysis of populist party supporters across European democracies. West European Politics, $44(3): 1-26$.

Voeten, E. (2017). Are people really turning away from democracy? https://www.journalofdemocracy.org/wpcontent/uploads/2018/12/Journal-of-Democracy-Web-Exchange-Voeten_0.pdf.

Wass, H. (2007). The effects of age, generation and period on turnout in Finland 1975-2003. Electoral Studies, $26(3): 648-659$.

Weyland, K. (2020). Populism's Threat to Democracy: Comparative Lessons for the United States. Perspectives on Politics, 18(2):389-406.

Wolfinger, R. E. and Rosenstone, S. J. (1980). Who Votes?. New Haven: Yale University Press.

Wroe, A. (2014). Political trust and job insecurity in 18 European polities. Journal of Trust Research, $4(2): 90-112$.

Wu, C. and Wilkes, R. (2018). Finding critical trusters: A response pattern model of political trust. International Journal of Comparative Sociology, 59(2):110-138.

Wuttke, A., Gavras, K., and Schoen, H. (2020). Have Europeans Grown Tired of Democracy? New Evidence from Eighteen Consolidated Democracies, 1981-2018. British Journal of Political Science, pages 1-13.

Zilinsky, J. (2019). Democratic deconsolidation revisited: Young Europeans are not dissatisfied with democracy. Research and Politics, 6(1):2-9. 